\title{
Belin:

Olivier Christin, Fabrice Flückiger, Naïma Ghermani (Éd.), Marie mondialisée. L'Atlas Marianus de Wilhelm Gumppenberg et les topographies sacrées de l'époque moderne, Neuchâtel, Éditions Alphil-Presses universitaires suisses, 2014, 256 p., ISBN 978-2-940489-527

Philippe Martin

DANS REVUE D’HISTOIRE MODERNE \& CONTEMPORAINE 2017/1 (Nº 64-1), PAGES 188 À 190 ÉDITIONS BELIN

ISSN $0048-8003$

ISBN 9782410008623

DOI 10.3917/rhmc.641.0188 


\section{Comptes rendus}

Pierre-Yves Beaurepaire (Éd.), Penser l'Europe du XViII ${ }^{\mathrm{e}}$ siècle en La communication en Europe. termes de "procès de communication" est De l'âge classique au siècle des Lumières, l'ambition de cet ouvrage issu d'un travail collectif dans le cadre du programme

ANR CITERE (Circulations, territoires et Paris, Belin, 2014, 365 p., ISBN 978-2-7011-8252-0

réseaux en Europe de l'âge classique aux Lumières). Centré sur la question du développement et des mutations de la communication savante au XVIII ${ }^{\mathrm{e}}$ siècle, il aborde de manière concrète, sous la forme de vingt-cinq études de cas, des situations de communication, le plus souvent épistolaires, à l'échelle individuelle ou institutionnelle. L'accent est mis sur la spatialisation des phénomènes étudiés, avec près de 76 créations cartographiques qui constituent la principale originalité de l'ouvrage. La communication s'entend ici dans un sens très large, sous l'angle matériel (route, guides), éditorial (périodiques savants, imprimés), institutionnel (bibliothèques, académies), épistolaire (correspondances scientifiques).

Les infrastructures sont abordées par le biais de succès éditoriaux comme la Carte générale des Postes de John Rocque (1758) ou l'Itinéraire des routes les plus fréquentées de Louis Dutens (1775) dont ressortent des cartes de synthèse sur les principales routes internationales (S. Blond). Autre publication à connotation "touristique" débouchant sur une cartographie des visiteurs: la liste des invités les plus prestigieux qui se rendent chaque semaine dans la ville thermale de Spa, pôle d'attraction de l'élite européenne à partir des années 1750. Le plan retouché de Spa en 1770 témoigne de la capacité du divertissement à organiser l'espace urbain. Mais derrière les vitrines de cette Europe de la mobilité, le schéma global reste bien celui de la lenteur et de la difficulté des déplacements.

Les savoirs circulent, mais les hommes peinent parfois à s'intégrer, comme le montre M. Virol avec le cas d'un ancien collaborateur de Vauban, chassé par le climat d'intolérance de la fin du règne de Louis XIV. Inversement, les structures académiques regorgent de témoignages positifs d'une communication savante en expansion et tournée vers la coopération européenne: un tiers des scientifiques recrutés par l'Académie de Bruxelles étaient étrangers. La lettre et le voyage nourrissaient les travaux académiques de l'Europe savante: ceux du Portugais Magellan (1722-1790) contribuèrent à la diffusion de la révolution chimique de Lavoisier (Pierre-Yves Beaurepaire); ceux de James Jurin établirent un réseau météorologique au service de la Royal Society: de 1723 à 1735, 74 correspondants établis dans 63 villes en Europe, Amérique et Asie envoyèrent leurs observations ( $M$. Collart). La correspondance du Dijonnais Louis-Bernard Guyton de Morveau (1737-1816) et les voyages de son disciple, le président Grossart de Virly (1754-1805), visaient à dresser un état des lieux de la connaissance européenne en matière de chimie (P. Bret).

Plus informelle, mais obéissant aux règles implicites d'une culture commune, la République des Lettres témoigne d'un enchevêtrement des réseaux interpersonnels; celui du suisse Haller, avec ses 1200 correspondants, forme le plus vaste réseau savant du XVIII ${ }^{\mathrm{e}}$ siècle (F. Catherine). Au terme de "réseau», A. McKenna préfère celui de "constellation philosophique" (Mulsow, 2009) pour décrire le fonctionnement en cercles et relais des correspondants de Bayle participant au cours des années 1692-1696 à son projet de Dictionnaire historique et critique qui substituait l'espace 
intellectuel et égalitaire de la République des Lettres à celui, pamphlétaire, de la communication politique ayant vu sa défaite contre Jurieu.

Dans cette accélération de la communication savante, l'étape déterminante fut la fondation à Paris et à Londres du fournal des Savants et des Philosophical Transactions en 1665, suivie par celle des Acta Eruditorum (Leipzig, 1682), puis par une vague de créations au XVIII ${ }^{\mathrm{e}}$ siècle, notamment de 1760 à 1790 (J. Peiffer). Chaque mois, ces périodiques en interaction constante rendaient compte de l'actualité scientifique. Les cas étudiés confirment la domination du français dans les échanges scientifiques et littéraires: les travaux des académies de Berlin, Saint-Pétersbourg et Turin étaient diffusés dans cette langue; les références bibliographiques françaises dominent dans les périodiques turinois et napolitains (M. Conforti et P. Delpiano), ainsi que dans la presse mexicaine entre 1768 et 1788 (P. Bret). Les périodiques savants français opèrent une sorte de filtrage de la science européenne grâce aux traductions et recensions d'ouvrages étrangers.

Les cantons suisses constituaient une plaque tournante pour la diffusion de la production savante italienne dans l'espace francophone, même si le naturaliste italien Lazzaro Spallanzani (1729-1799) cherchait aussi à publier en allemand et en anglais (A. Bruschi). La Poméranie suédoise constitue un autre espace multiculturel où la communication savante put s'épanouir après l'établissement de relations postales à partir de Stralsund, la création du Stralsundischer Relations-Courier en 1689, puis d'une presse savante au siècle suivant, en lien avec la fondation de l'Académie de Stockholm en 1739. La région constitua un carrefour de traductions entre l'allemand et le suédois, assurant la diffusion de la science minéralogique suédoise (A. Önnerfors). Le travail de traduction était également au cœur de l'activité de ceux qui, de 1780 à 1792 à Dijon, traduisaient en français à l'intention de la presse savante des ouvrages de chimie et minéralogie écrits en latin, allemand, suédois, anglais, italien (P. Bret).

La notion de "dispositif de communication", dérivée de Michel Foucault et utilisée en sociologie des médias, accompagne plusieurs études de cas. Pour H. Hermant, le "dispositif communicationnel» mis en place par don Juan José de 1668 à 1669 permet d'expliquer le passage de la "faction" à un "mouvement d'opinion" en sa faveur; cette notion remplacerait ainsi avantageusement celle d'opinion publique. P.-Y. Beaurepaire livre ses réflexions sur les limites du concept de réseau qui avait été à l'honneur lors d'un colloque tenu à Arras (La plume et la toile, 2002). Très flexible, la notion devait désormais affronter des cas individuels: celui de Jacques Pérard (1713-1766), pasteur réformé à Stettin à partir de 1750, montre la construction d'un espace de sociabilité épistolaire en quête de reconnaissance au sein de la République des Lettres. M. Gellard analyse pour sa part les dispositifs de communication mis en place par Catherine de Médicis pendant les guerres de Religion pour gommer la dimension confessionnelle du conflit et convaincre les princes européens de ne pas soutenir des sujets révoltés. Il faut admettre qu'en dépit de sa récurrence, la notion sert assez inégalement les analyses proposées.

La réflexion sur la territorialisation des bibliothèques s'appuie sur un observatoire unique et passionnant, celui de Göttingen: malgré les stigmates de la guerre de Trente Ans (3500 habitants au cœur d'un désert culturel), le gouvernement du Hanovre décide d'y fonder une université en 1734 ainsi qu'une bibliothèque universitaire (qui multiplie sa collection par onze en soixante ans), bientôt suivies d'un journal savant, les Göttingische Zeitungen von Gelehrten sachen (1739) puis d'une Académie des Sciences (1751). Ces quatre institutions piliers de la République des 
Lettres ont totalement remodelé l'espace urbain et assuré à la ville un rayonnement international (E. Chapron et A. Saada).

La communication est aussi envisagée sous l'angle des liens faibles: le cas de l'arrestation de colporteuses parisiennes en 1766 fait intervenir de petits réseaux locaux et provinciaux dans la distribution clandestine du livre prohibé; ils parviennent néanmoins à atteindre tout type de lectorat, dans les espaces parisiens les plus proches des autorités (D. Droixhe).

Le dernier aspect abordé est la dimension affective du processus de communication: dans le cas du projet de mariage entre Élisabeth Ire Tudor et le duc d'Anjou en 1570-1571, c'est de "communication amoureuse en absence" qu'il s'agit, de conventions rhétoriques et de règles tacites exprimant tout un jeu de séduction par médiateurs interposés (M. Gellard). L'affection d'un père ressort de la correspondance entre Philippe II et ses filles (H. Hermant). L'amitié et le partage d'une même curiosité scientifique sont au cœur de la correspondance entre Latapie et le fils de Montesquieu, permettant à ce dernier une sorte de voyage italien par procuration entre 1775 et 1777 (G. Montègre); l'amitié et une même passion pour la botanique unissent pendant près de trente ans le curé Dominique Chaix et le docteur Dominique Villars, aboutissant à la publication d'une Histoire des plantes du Dauphiné en 1786-1789 (K. Loiselle).

Les études de cas s'achèvent donc avec la mutation des échanges par la force montante de "l'individualisme affectif»: les liens d'amitié - et pas seulement les idées - sont aussi au cœur de la production scientifique du XVIII ${ }^{\mathrm{e}}$ siècle. Pour autant, la diversité des situations de communication envisagées parvient difficilement à la vision globale d'un "procès européen de communication"; elle permet en revanche d'en saisir la complexité: après les développements de la route, de la poste et de la presse, des institutions scientifiques acquièrent au XVIII ${ }^{\mathrm{e}}$ siècle un pouvoir organisateur et structurant d'espaces de communication, à la fois physiques et intellectuels.

Stéphane HAFFEMAYER Université de Caen-Normandie

Olivier Christin, fabrice flückiger, NaÏma Ghermanı (ÉD.),

Marie mondialisée. L'Atlas Marianus de Wilhelm Gumppenberg et les topographies sacrées de l'époque moderne,

Neuchâtel, Éditions Alphil-Presses universitaires suisses, 2014, 256 p., ISBN 978-2-940489-52-7
Le XVII siècle, période d'épanouissement d'une géographie universelle et d'une nouvelle approche de la classification des savoirs, est le temps des encyclopédies. On range les lieux, les villes, les animaux, les matériaux, etc. La religion ne peut pas y échapper. À la suite de Ferry de Locre (1608), nombre d'ecclésiastiques se plaisent à des géographies religieuses: Jean Buzelin (1625), Augustin Wichmans (1632), Narcís Camós (1657), Vincent Laudun (1665-1669). En publiant son Atlas Marianus (1657-1659), le jésuite Wilhelm Gumppenberg (1609-1675) s'inscrit dans ce mouvement, tout en le renouvelant totalement. Persuadé d'être élu par Notre-Dame, qui lui aurait assigné une mission en juin 1643, il assure: "Mon idée est de démontrer combien le monde doit à Marie et combien il peut en attendre» (p. 118). Avec un implacable esprit rigoureux, il propose des notices toutes construites sur le même modèle, ce qui permet à son lecteur de se retrouver facilement et de se rassurer: si les images sont diverses, Marie est une. 
Elles sont accompagnées de preuves, de citations, de références et d'un index comprenant des centaines d'entrées, autant d'aides à la consultation, de guides dans un territoire marial organisé par Gumppenberg. Elles fixent de manière quasiofficielle le récit des miracles, de l'invention des statues, du développement des dévotions. En outre, des centaines d'illustrations (1200 pour l'édition de 1672) donnent "à voir» les images mariales priées. Se voulant exhaustive, mais sachant que c'est une illusion, l'œuvre s'annonce universelle et gagne sa légitimité. L'étude d'exemplaires conservés montre, par la présence de marginalia, qu'elle a servi à des prédicateurs et à des mariologues, pour qui elle est devenue un répertoire d'exemples. Il est en revanche difficile de saisir les éventuels usages pieux. Au-delà de ces lectures par morceaux, elle est une pièce maîtresse d'un savoir se voulant totalisant, une entreprise mariale remarquable.

Ce bel ouvrage de synthèse, composé de quinze articles, abondamment et remarquablement illustré, est issu des travaux d'une équipe animée par Olivier Christin, Fabrice Flückiger et Naïma Ghermani. Les auteurs s'intéressent d'abord à "nature et surnature", occasion de discuter ce que l'on pourrait considérer comme des contradictions: l'Église est en lutte contre les superstitions mais diffuse les récits sur les miracles; elle critique les fantômes mais développe une théologie du Purgatoire. En réalité, il n'y a là aucune difficulté mais une volonté de distinguer entre œuvre divine et erreurs. Ils passent ensuite aux "topographies» sacrées à un moment où une nouvelle perception de l'espace s'épanouit. Cette prise en compte du lieu amène Gumppenberg à trancher radicalement avec les livrets de pèlerinage traditionnels. Il est vrai que l'atlas est un chef-d'œuvre du travail jésuite, dimension abordée dans une troisième partie. Dès 1652, plusieurs centaines de correspondants sont mobilisés, tous conscients de mener un combat au service de la Contre-Réforme mariale. Si l'Atlas Marianus est bien une œuvre collective, W. Gumppenberg en revendique la paternité car il est celui qui classe, qui ordonne, qui structure. Il est aussi celui qui commande les images, cœur de la quatrième partie. L'atlas n'est pas simplement un recueil de gravures; il est une "défense en actes" (p. 206).

L'Atlas Marianus n'est pas une topographie ordinaire, il développe une «stratégie sous-jacente" (p. 120) au service d'un "projet politique et religieux" (p. 19). Son ambition est triple. Elle est d'abord scientifique, car il prend sa place "dans les combats de la science jésuite» (p. 41). Il est "un magasin ordonné» (p. 109), approche originale de la classification des savoirs car il ne forme ni un palmarès, ni une chronologie, ni un itinéraire. Il constitue une réfutation des positions coperniciennes, une arme contre tous les empiétements contre le religieux, un outil d'affirmation de positions intellectuelles, un manifeste dans les luttes confessionnelles. Toutes les disciplines sont convoquées. Ainsi, le magnétisme est enrôlé pour expliquer la propagation de la puissance mariale à partir d'une image capable de transférer sa force à une réplique sans perdre son pouvoir, comme le fait un aimant. Cette entreprise est tout au service de la Vierge. Celle-ci n'est pas simplement la protectrice que prient les fidèles, un intermédiaire obligé entre le Ciel et les hommes qu'elle protège des colères divines. Elle remplace l'Atlas antique soutenant la voûte étoilée, elle est le ressort de la mécanique céleste, elle se situe au centre d'un nouveau registre zodiacal. Elle est véritablement la Reine des Cieux. Gumppenberg investit le champ scientifique pour en refuser l'émancipation et y placer Marie qui annonce la fin des temps anciens, voués au passé antique et à la division confessionnelle. Elle est la mère d'un «univers signifiant et plein où s'exercent de puissantes forces visibles et invisibles" (p. 43). 
La deuxième ambition est politique. À l'exception de deux séjours à Rome, Gumppenberg passe toute sa vie en Bavière; c'est d'ailleurs à Munich que sont publiées la majorité des éditions de son atlas. La géographie mariale qu'il dessine n'est "pas une photographie exacte et neutre" (p. 228). Si 5\% des notices concernent des sanctuaires non-européens, plus de la moitié s'attachent à des pèlerinages implantés dans les terres contrôlées par les Habsbourg. En marquant le territoire et les frontières confessionnelles, il participe à la construction des identités nationales. Il contribue à définir la Pietas Austriaca en lui donnant une dimension mariale.

La troisième ambition est religieuse. En composant son atlas, Gumppenberg défend le principe du miracle qui est possible et raisonnable car il n'est pas une rupture de l'ordre de l'univers. Dieu agit dans le monde en Notre-Dame à travers ses images. Elle se manifeste dans des matériaux simples, proches des hommes, loin du luxe tapageur de l'argenterie liturgique. Le texte de l'atlas constitue une défense même de ces images, une "théologie de l'image en images" (p. 188). Le parcourir, c'est parfois avoir l'impression de regarder à travers un «kaléidoscope d'images mariales» (p. 197). Mettant en scène la diversité, Gumppenberg veut dégager l'unité car Marie est à la fois universelle et multiple. Elle est mondiale tout en sachant parler aux hommes leurs langues locales.

L'Atlas Marianus est une réussite intellectuelle et éditoriale. Les premières éditions se sont vendues à 6000 exemplaires. Entre 1657 et 1717, il connaît treize éditions (six en latin et sept en allemand) publiées à Ingolstadt, Munich, Dillingen et Prague; il faut ajouter les traductions et les adaptations jusqu'au milieu du XIX ${ }^{\mathrm{e}}$ siècle avec, en 1839-1847, le travail d'un prêtre italien, Agostino Zanella, qui y ajoute de nouvelles images mariales, surtout italiennes. Le succès est celui d'«une ambition universaliste clairement revendiquée qui faisait bon ménage avec un particularisme localiste» (p. 232). Il est aussi celui d'une «illustration parfaite du principe central d'organisation politique et religieuse" (p. 21).

Martin GierL, L'historiographie allemande des LuGeschichte als präzisierte Wissenschaft. Johann Christoph Gatterer und die Historiographie des 18. Jahrhunderts im ganzen Umfang,

Stuttgart-Bad Cannstatt, Frommann-Holzboog, 2012, 458 p., ISBN 978-3-7728-2568-2 mières est un champ peu connu en France, si ce n'est à travers des figures comme celles d'Emmanuel Kant et Johann Gottfried Herder, davantage enclines à s'interroger sur le sens de l'histoire que sur la construction de l'histoire elle-même. Outre-Rhin, l'Aufklärungshistorie occupe également une place particulière dans la mesure où l'historisme du XIX ${ }^{\mathrm{e}}$ siècle a tenté d'effacer l'historiographie du $\mathrm{XVIII}^{\mathrm{e}}$ siècle pour se présenter en unique fondateur de la science historique. Mais, depuis les années 1970, plusieurs travaux ont réévalué le rôle du XVIII siècle dans l'histoire de l'Histoire, notamment autour de Peter Hanns Reill, Georg G. Iggers et Jörn Rüsen, fondateurs de la collection "Fundamenta Historica", dont l'ouvrage de Martin Gierl constitue le quatrième volume.

Johann Christoph Gatterer (1727-1799) est la figure fondatrice de l'«école historique de Göttingen». De 1759 à 1799, il a été professeur d'histoire à l'université de Göttingen, université phare de l'Aufklärung. Toute son œuvre est animée par l'ambition de doter 
l'histoire de fondements scientifiques - de "préciser l'histoire" - et de produire une histoire "dans toutes ses parties» (im ganzen Umfang). Gatterer a fondé le premier Institut d'histoire, une institution consacrée à la fois à l'enseignement et à la recherche, et qui est considérée comme l'ancêtre du séminaire de recherche. C'est au sein de cet institut que Gatterer a fondé la première revue historique scientifique. Il est également connu pour ses nombreux manuels sur les sciences auxiliaires de l'histoire - la chronologie, la numismatique, l'héraldique, la généalogie, la diplomatique, la géographie - qu'il a contribué à redéfinir, ainsi que pour ses ouvrages d'histoire universelle.

Jusqu'à ce jour, aucun travail substantiel ne lui avait été consacré, malgré son importance et la richesse de sa production. «Ma question est simple», écrit M. Gierl dans son introduction, «je veux savoir ce que signifiait "l'histoire dans toutes ses parties" pour Gatterer et comment il s'y est pris pour produire une telle histoire». Quatre cents pages plus loin, il ne fait aucun doute que l'auteur a rempli son contrat, mais le chemin à parcourir est difficile.

En effet, ce livre est complexe et déroutant, du fait que son objet lui-même l'est: une historiographie qui nous est étrangère parce que son auteur l'a conçue comme une science au sens moderne du terme et qu'elle n'est pas construite de façon discursive. Pour Gatterer, la démarche historique impliquait de mesurer, compter, classer, représenter, et son historiographie se présente sous forme de tableaux, de diagrammes et de cartes, ce qui a conduit $\mathrm{M}$. Gierl à procéder lui-même de façon non linéaire. $\mathrm{Au}$ regard de l'objectif de celui-ci, il n'était pas possible de faire autrement. Dans la mesure en effet où le projet de Gatterer était de livrer une histoire «dans toutes ses parties", et que l'ensemble de ses travaux était au service de ce projet, il était nécessaire de suivre Gatterer dans "toutes les parties» de son œuvre et de montrer les liens entre elles. Ainsi, à l'inverse des quelques travaux qui ont été produits sur Gatterer, et qui distinguent entre le géographe, le cartographe, le promoteur de l'histoire universelle, etc., M. Gierl est parti du principe - irréfutable - que tous ces Gatterer ne constituaient qu'un seul Gatterer, celui qui avait pour but d'écrire une histoire universelle sur des fondements scientifiques et dont toute l'œuvre visait à développer les outils et la méthode pour le faire.

M. Gierl a saisi à bras-le-corps son objet. Son choix n'a pas été de se concentrer sur les résultats de Gatterer, mais de nous faire suivre pas à pas les étapes suivies par l'auteur pour élaborer cette histoire. Car c'est bien le portrait d'un constructeur, d'un ouvrier de l'histoire, d'un expérimentateur scientifique que l'auteur dresse de Gatterer. De là, une description minutieuse et concrète des outils que ce dernier a patiemment mis au point pour élaborer cette histoire.

Le premier chapitre présente l'Institut d'histoire ainsi que le projet théorique et pratique de Gatterer. Le deuxième chapitre porte sur les sciences auxiliaires dont la finalité devait être de "préciser l'histoire», c'est-à-dire de l'établir sur des faits vérifiés. Tout d'abord, la chronologie, pour situer les événements dans le temps, mais surtout pour pouvoir dater les débuts de l'histoire, ce qui impliquait d'unifier dans une même chronologie les différents calendriers. Ensuite, la géographie - ou plutôt la géographie historique et mathématique - afin d'ancrer les événements dans des lieux et de décrire l'espace. Enfin, la généalogie, l'héraldique, la numismatique, la diplomatique et la statistique pour reconstituer l'histoire des règnes et des peuples. Dans chacune de ces disciplines, Gatterer a établi des règles précises.

Le troisième chapitre reconstitue les tentatives de Gatterer pour construire un système historique. Comment passer de l'enregistrement des singularités à leur 
effectivité au sens d'une causalité ? Il s'agissait ici de passer d'une histoire statique - du cabinet de curiosités - à la mise en évidence d'une dynamique de l'histoire à travers la reconstruction de la chaîne des évolutions. Pour saisir ce mouvement, Gatterer a construit une série d'instruments historiographiques qui fonctionnaient ensemble: le "Linneaismus graphicus» soit la méthode de Linné appliquée à la diplomatique pour reconstruire l'histoire à partir du classement des chartes, puis du repérage de leur succession; la chronométrie pour dater les sources; la cartographie pour faire le lien entre les descriptions historique et géographique; la météorologie parce que Gatterer considérait le climat comme facteur déterminant de l'évolution. Son système historique reposait sur la combinaison de ces quatre paramètres.

Le dernier chapitre présente l'histoire universelle de Gatterer «dans toutes ses parties». C'est à présent une histoire sécularisée, des civilisations, construite à partir de tableaux, de cartes et de diagrammes et qui s’intéresse aux périodes de révolutions mesurées à l'aune de la succession des dynasties et des migrations de population depuis l'Antiquité jusqu'à la période la plus récente. Ce n'est pas l'un des moindres apports de Gatterer, souligne M. Gierl, que d'avoir assigné une place au Moyen Âge entre les temps anciens et une période moderne. Ce chapitre présente également les manuels de Gatterer sur l'histoire universelle dans le contexte de l'essor général de l'histoire universelle d'une part et, d'autre part, en situant la production de l'historien dans les enjeux locaux de l'historiographie à Göttingen et de la lutte autour de l'histoire universelle qui opposa Gatterer à August Ludwig Schlözer, puis à Herder à la veille de l'historisme.

Ce livre est semblable à son objet: il représente un véritable ouvrage scientifique d'histoire, au sens où il ne désolidarise pas les résultats de Gatterer des différentes étapes de sa démonstration; il montre également que l'histoire peut s'écrire différemment de ce que nous connaissons aujourd'hui. Ce faisant, à distance d'une philosophie de l'histoire, il nous permet d'entrer dans les ressorts de cette historiographie du XVIII ${ }^{\mathrm{e}}$ siècle que Gatterer incarnait de façon paradigmatique, et à laquelle il a donné un élan décisif en ce qui concerne la construction de l'histoire aussi bien que l'organisation de la discipline. Les nombreuses reproductions qui accompagnent le texte sont moins des illustrations que des outils nécessaires pour comprendre cette historiographie qui faisait de l'élément visuel un outil comme un argument de vérité.

Anne Saada

Pays Germaniques (UMR 8547), CNRS-ENS

Gilles MontèGre, Cet ouvrage, issu d'une thèse souteLa Rome des Français au temps des Lumières. Capitale de l'antique et carrefour de l'Europe

(1769-1791), nue en décembre 2006, a pour objectif de remettre en question les représentations convenues d'une Rome en marge

Rome, École française de Rome, 2011, 624 p., de l'Europe des Lumières au cours de la ISBN 978-2-7283-0882-8 seconde moitié du XVIII e siècle. Il s'inscrit en cela dans la continuité d'une historiographie (italienne, notamment) qui a connu de profondes mutations depuis deux à trois décennies et tend désormais à revaloriser la place et le rôle de Rome comme capitale culturelle à cette époque.

La période étudiée (1769-1791) correspond à l'ambassade romaine du cardinal François de Bernis (1715-1794), mais aussi au moment où Rome s'intègre au mouvement des Lumières: les années 1770 et 1780 sont en effet marquées, selon 
l'auteur, par une sécularisation et une féminisation du champ culturel romain qui contribuent à faire de la Ville Éternelle un lieu d'échange culturel privilégié, où sont produits et diffusés des savoirs.

L'ouvrage s'organise en trois grandes parties qui étudient tour à tour la communauté des Français de Rome et ses formes particulières de sociabilité ("Les acteurs et les formes de l'échange culturel»), les institutions qui cherchent à encadrer cette communauté et à dominer le champ de la médiation culturelle franco-romaine ("Savoirs et pouvoirs»), et les principaux terrains d'investigation des Français dont le séjour romain relève des mobilités savantes ("Les horizons de la recherche savante»).

La communauté française étudiée par Gilles Montègre comprend à la fois des voyageurs (dont certains effectuent alors leur Grand Tour) et des résidents (diplomates, artistes - ceux qui accompagnent les gentilshommes du Grand Tour comme ceux qui viennent parfaire leur formation à l'Académie de France). L'auteur entreprend de cartographier leur présence à Rome, et confirme leur concentration autour du quartier très cosmopolite de la place d'Espagne (l'une des annexes de l'ouvrage permet de constater que la grande majorité de ces Français ont, en fait, résidé dans trois paroisses, celles de Santa-Maria-del-Popolo, de Santa-Maria-inVia-Lata et de San-Lorenzo-in-Lucina). Il présente ensuite les lieux et les formes de la sociabilité de ces Français, en insistant sur le rôle des salons (diplomatiques comme celui du cardinal de Bernis, ambassadeur de France auprès du Saint-Siège; artistiques comme celui qui était tenu par Angelica Kaufmann; bourgeois comme celui de Maria Pizzelli) et des académies (notamment celle des Arcades, dont il montre qu'elle s'est assez largement ouverte, dans les années 1770 et 1780, à des Français d'origines sociales très diverses - les roturiers représentant d'ailleurs un peu plus d'un tiers du total - et à des membres du clergé éclairé comme le père François Jacquier). Cette première partie est l'occasion, en outre, de soulever la question de l'acculturation des Français de Rome (différente, bien entendu, en fonction de la durée de leur séjour) et des dynamiques d'intégration et d'exclusion qui sont à l'œuvre au sein des lieux de sociabilité étudiés.

G. Montègre se penche ensuite sur le rôle des principales institutions françaises susceptibles de favoriser les échanges culturels entre la société romaine et leur pays d'origine, notamment la cour d'ambassade du cardinal de Bernis, les ordres religieux (comme les dominicains du couvent de Santa-Maria-sopra-Minerva et les minimes de La-Trinité-des-Monts) et, de manière moins officielle, la loge maçonnique de la Réunion des Amis Sincères à l'Orient de Rome fondée en 1787 (l'auteur rappelle, dans ce dernier cas, que c'est précisément la présence d'une communauté française à Rome qui permet, entre 1787 et 1789, l'éclosion et l'activité d'une loge maçonnique en dépit de la répression pontificale).

Il montre d'abord la manière dont le cardinal de Bernis a cherché à affirmer, grâce à sa longévité dans le poste, son autorité sur les artistes de l'Académie de France et la confrérie de Saint-Louis-des-Français, mais aussi un rôle d'hôte incontournable pour les voyageurs européens de passage à Rome (le Palais de Carolis, siège de l'ambassade de France, ne devient-il pas sous son ministère «l'auberge de la France au carrefour de l'Europe" ?). Dans tous ces rôles, il cherche avant tout à faire rayonner le prestige de la France dans la capitale de la chrétienté catholique. Il doit, quoi qu'il en soit, faire face à la concurrence d'autres cours d'ambassade (notamment celle de l'ambassadeur de Malte auprès du Saint-Siège) et à l'émergence de certaines résistances à son autorité. 
L'étude du rôle de certains couvents dans la circulation des savoirs entre France et Italie est sans doute moins attendue, mais elle contribue à nuancer la vision d'un catholicisme par essence obscurantiste qui reste assez largement attachée à l'image de Rome à l'époque moderne. G. Montègre se penche particulièrement sur le parcours et l'activité de deux hommes, un dominicain (Gabriel Fabricy) et un minime (François Jacquier, dont le rôle fut essentiel dans la diffusion des idées newtoniennes en Europe) : ce choix lui permet de mettre en valeur les réalités et les limites de l'effort entrepris par certains ordres religieux pour concilier la tradition catholique et la modernité des Lumières.

Sont analysées enfin les conditions d'étude des savants français de passage à Rome (notamment le naturaliste François de Paule Latapie, le médecin René Desgenettes, le physicien Charles-Marie de la Condamine) et la manière dont ils ont fait de leur séjour à Rome l'occasion de recueillir et de produire des savoirs. La Ville en effet n'est pas seulement, comme le répète l'auteur, un "conservatoire» de la culture antique; elle est aussi un "creuset culturel dans l'Europe du XVIII siècle" en raison de son cosmopolitisme, et même un véritable terrain d'étude pour des savants qui s'intéressent à sa faune et à sa flore ainsi qu'à la formation de ses paysages. Les bibliothèques romaines par exemple, qu'elles dépendent d'institutions religieuses (Vaticane ou collections d'ordres religieux comme la bibliothèque Casanatense) ou de familles patriciennes (Barberini, Corsini), ont constitué pour les savants français comme François de Paule Latapie de véritables lieux d'étude en raison de leur accessibilité (d'ailleurs variable en fonction des lieux) et de la grande richesse de leurs fonds. De même est évoqué, à titre d'exemple, le rôle joué par le géologue Dolomieu dans la remise en cause de certains fondements des théories esthétiques sur la supériorité de l'art grec du prussien Winckelmann, dans la mesure où il met à profit son expertise scientifique pour réévaluer l'origine de la célèbre statue de l'Apollon du Belvédère. L'auteur rappelle, à ce propos, le nouveau rôle joué par les salons romains comme instances de légitimation des savoirs puisque c'est par leur intermédiaire que Dolomieu a pu diffuser ses conclusions.

G. Montègre, on l'aura compris, cherche à démontrer le rôle de médiateurs culturels joué par les Français qui ont séjourné dans la Ville Éternelle pour une durée plus ou moins longue; il entend également mettre en lumière la fonction de "carrefour" de cette dernière au sein de l'Europe des Lumières, quoiqu'avec un temps de retard sur les autres capitales culturelles européennes. Son travail témoigne d'une excellente connaissance de l'historiographie italienne sur le sujet, profondément renouvelée depuis les années 1990, et s'appuie sur un corpus très riche (registres d'état des âmes, archives d'institutions culturelles - celle de l'Académie des Arcades ou de l'Académie San Luca - ou d'ordres religieux, récits de voyage, correspondances, traités, etc.). Il faut souligner, enfin, le grand intérêt des annexes, qu'il s'agisse de la présentation synthétique des Français ayant séjourné à Rome au cours de la période étudiée ou de la volonté de «territorialiser les savoirs dans la ville»: la Nuova Pianta di Roma, élaborée par Giambattista Noli en 1748, permet ainsi de localiser les différents lieux de savoirs dans la ville (librairies, bibliothèques, centres d'enseignement, académies, musées).

La démarche de G. Montègre s'avère stimulante. Elle devrait ouvrir la voie à l'étude d'autres groupes nationaux ayant résidé dans la Ville Éternelle dont le cosmopolitisme a été maintes fois souligné; elle démontre combien la démarche de spatialisation des objets d'histoire culturelle peut être féconde. 
Christophe Morin,

Au service du château. L'architecture des communs en Île-de-France au XvIII siècle, Paris, Publications de la Sorbonne, 2008, 471 p., ISBN 978-2-85944-580-5
Christophe Morin se détourne ici du corps du logis, généralement privilégié dans l'étude du phénomène castral, pour en dévoiler l'envers du décor mais aussi en saisir la logique d'ensemble à travers l'analyse des fonctions d'utilité, révélant ainsi les interactions qui se nouent entre logis, jardins, communs et dépendances. C'est par ce biais que l'auteur reformule la question de l'habitat noble aux champs, dont le développement répond à la vitalité de la croissance urbaine au siècle des Lumières. Les châteaux construits ou remaniés au XVIII ${ }^{\mathrm{e}}$ siècle dans le Bassin parisien constituent un terrain favorable à cette tentative, la proximité de la capitale faisant de l'Île-de-France un «laboratoire formel incomparable» (p. 19).

Le titre original de la thèse dont l'ouvrage est issu, Bâtiments d'utilité: accès et abords du château au XVIII siècle, en évoquait plus précisément la problématique que le titre retenu pour la publication. L'auteur explique en effet d'emblée que c'est l'indétermination du terme "communs", oscillant entre des acceptions très restreintes - le service de la bouche - ou très larges - tout ce qui n'est pas le logis -, qui l'a conduit à élaborer le concept de "bâtiments d'utilité». Revendiquant les notions d'agrément et d'utilité mobilisées par l'architecte Jacques-François Blondel pour caractériser le fonctionnement d'une maison noble, l'auteur fait de la valeur d'usage le critère discriminant des différentes composantes du château. Sont alors regroupés de manière cohérente des bâtiments souvent artificiellement distingués entre communs et dépendances, tels que cuisines, offices, orangeries, glacières, logements domestiques, écuries, chenils, etc. Mais ces lieux de service, de conservation, d'habitation et d'abri ne prennent sens qu'autour du logis du maître, dont ils contribuent à manifester la position sociale. Parties prenantes des "accès et abords du château» ainsi que des espaces de circulation irriguant ce dernier, ces bâtiments sont donc à resituer dans l'économie d'un plan d'ensemble, voire d'un programme. L'ouvrage ambitionne ainsi de dépasser l'analyse fonctionnelle, technique et architecturale de l'agencement des bâtiments d'utilité afin de rendre compte de leur valeur esthétique et symbolique dans le cadre d'une réflexion globale sur la conception et l'organisation du château.

L'échantillon étudié témoigne en effet autant de l'émergence de nouveaux styles et modes de vie que de la pérennité des modèles seigneurial et royal. L'idéal de la maison de campagne et le mythe du retour à la nature, le développement des décors rocaille puis «à la grecque» le disputent à la nécessité, exacerbée par les ambitions du monde de la finance, de distinguer le château, construit sur un fief par privilège royal, des autres habitations. Il convient notamment d'en souligner les attributs féodaux (colombier, auditoire de justice, chapelle) et d'affirmer le rang de son propriétaire par l'emploi de formes traditionnelles, telles que les cycles de cour graduant l'accès au logis, et de références explicites aux résidences royales. On imite ainsi les écuries de Versailles et l'orangerie de Saint-Cloud, ou encore des demeures devenues pour l'aristocratie le modèle de l'appropriation paradoxale par la monarchie de la "fiction d'habiter une petite maison", Bellevue, Choisy ou le petit Trianon.

Globalement, les architectes du XVIII ${ }^{\mathrm{e}}$ siècle revendiquent des principes de bienséance, d'efficacité et d'hygiène: c'est en vertu de ces critères, commandant de strictes séparations entre les maîtres et les serviteurs ou entre le propre et le sale, que sont encouragées les transformations visant à l'amélioration de l'agencement des espaces de service. Se développent par exemple dans les cuisines les fourneaux 
potagers (placés sous les fenêtres ou au centre de la cuisine) ou les adductions d'eau (puits intérieurs dotés de pompes à main; alimentation par des tuyaux en cuivre reliés au puits extérieur). Les recommandations des architectes n'en restent pas moins souvent lettre morte: préconisée dans les cuisines et les écuries pour lutter contre les incendies, dans les orangeries pour maintenir une température adéquate, la voûte est pourtant peu pratiquée car jugée trop onéreuse. De même, on continue à construire des cuisines en sous-sol, pourtant jugées malsaines, car il s'avère généralement trop compliqué d'aménager des cuisines en aile, nécessairement assorties d'un bâtiment symétrique et de passages de circulation vers le logis. Les cuisines en sous-sol présentent en outre l'avantage d'être dissimulées, conformément à l'idéal de la maison de plaisance prenant la forme d'un pavillon isolé, de plan massé, et autonome de tout bâtiment de service. Certains modèles peuvent donc entrer en concurrence comme certains principes en contradiction: l'hygiène peut être sacrifiée à la rapidité du service comme l'efficacité à l'agrément. C'est ainsi qu'il arrive qu'on renonce à orienter une glacière vers le nord, par souci d'ériger une fabrique pittoresque. Agencement et emplacement de ces espaces partagent donc les théoriciens et témoignent dans les réalisations étudiées d'arbitrages variés entre critères de convenance, contraintes matérielles ou topographiques et choix esthétiques.

C'est à partir de la seconde moitié du XVII ${ }^{\mathrm{e}}$ siècle que le château est conçu, sur le modèle du complexe versaillais, comme un ensemble auquel les communs s'intègrent si bien qu'ils forment un écrin pour le corps du logis. À Bagatelle, «la façade monumentale de l'aile de service» en vient même à "[servir] d'écran aux activités du personnel en même temps qu'elle offre un décor luxueux au logis, avec son exèdre centrale percée de niches d'inspiration antique" (p. 70). Ailleurs, des passages transversaux peuvent être aménagés pour escamoter les carrosses des invités et dégager en permanence la vue sur le corps de logis. Devant s'harmoniser avec le reste du domaine, les communs sont donc pris en compte dans les programmes de transformation, qui visent autant à l'affirmation du pouvoir du seigneur qu'à la recherche de son confort par la rationalisation du château. À Bonnelles (Yvelines) par exemple, la façade du corps de logis est régularisée tandis que les communs sont réorganisés autour de deux basses-cours rejetées à droite de l'avant-cour. Plus généralement, les motifs ornementaux se développent sur les bâtiments d'utilité, notamment au niveau des portails d'entrée, ce qui en fait les témoins, comme les autres bâtiments, du passage du style rocaille au style "éclectique» de la fin du siècle. Par bienséance, les communs doivent cependant être subordonnés au corps de logis: une moindre élévation, des matériaux moins nobles (la tuile au lieu de l'ardoise), l'emploi de l'ordre dorique, voire le recours aux modèles vernaculaires tendent ainsi à les caractériser.

Si l'anglomanie ne fut sans doute pas le seul vecteur de diffusion du modèle palladien de villégiature suburbaine, c'est cependant sous influence anglaise que le château tend à être aussi conçu comme un espace ouvert à la nature. Cela se traduit notamment par des tentatives pour intégrer celle-ci à la séquence d'accès au logis, et, au-delà, pour trouver un compromis spatial et architectural permettant de concilier les fonctions publiques et officielles du châtelain avec son aspiration à l'intimité. Se généralise donc la différenciation des types d'organisation des abords du château côté cour et côté jardin: à Mauperthuis (Seine-et-Marne), Ledoux oppose ainsi une entrée majestueuse et un parc à l'anglaise. On touche ici aux limites de la contamination du programme du château par celui de la maison de campagne. Les innovations sont finalement limitées par le cadre formel très strict qu'impose le château et s'expriment 
avant tout dans le vocabulaire décoratif. Faute de respecter les figures imposées par la convenance et les exigences de la représentation, le château métamorphosé en maison de plaisance perd en effet son identité et celle de son propriétaire, comme en témoigne le projet néo-palladien conçu pour le marquis de Goulet en 1789.

L'argumentation d'ensemble de l'ouvrage souffre de quelques défauts d'organisation interne, liés notamment à la difficile entreprise que représente la synthèse des diverses formulations architecturales rencontrées et des nombreuses références théoriques contemporaines mobilisées. La circulation et les formes d'appropriation de celles-ci pourraient d'ailleurs faire l'objet d'une recherche plus fouillée, afin de parachever le projet sous-jacent: participer par l'histoire de l'architecture à celle des mutations culturelles des Lumières. Par sa valeur heuristique, cette ambition essentielle n'en nourrit pas moins l'ouvrage, fort d'un corpus étendu, riche de belles annexes techniques (définitions, descriptions, plans) et dont les apports sont indéniables, par la rigueur avec laquelle sont analysés les agencements et les usages d'espaces trop souvent négligés. Ceux-ci s'avèrent en effet nécessaires à la compréhension de l'ethos noble et de ses traductions matérielles.

Pauline LeMAIGRE-GAFFIER Université Versailles-Saint-Quentin

\author{
Philippe de Carbonnières, \\ La Grande Armée de papier. \\ Caricatures napoléoniennes, \\ Mont-Saint-Aignan, Presses universitaires \\ de Rouen et du Havre, 2015, 184 p., \\ ISBN 979-10-240-0523-2
}

Ce livre est l'aboutissement de plusieurs années de travail de Philippe de Carbonnières, attaché de conservation au musée Carnavalet, responsable des collections de la Révolution et de l'Empire au cabinet des arts graphiques du musée. Publié par un éditeur universitaire, l'ouvrage a bénéficié

du soutien financier de la fondation Napoléon. De facture élégante, il ne compte pas moins de soixante-sept planches en couleurs ou noir et blanc expliquées individuellement, et huit autres, en couleurs, destinées à illustrer une longue introduction méthodologique.

Qualité formelle, lisibilité et efficacité sont les maîtres-mots qui ont présidé à la fabrication de ce livre. P. de Carbonnières jouit d'une grande facilité pour accéder quotidiennement à son corpus, qu'il connaît donc très bien. Si la lecture de l'ouvrage est roborative, tant l'iconographie et a fortiori la caricature restent encore souvent marginalisées et volontiers réduites à une simple fonction illustrative, le point de vue de l'auteur, exposé dans son introduction comme dans le sous-titre du livre, laisse perplexe. Il soutient en effet qu'il existerait une production importante de caricatures pro-napoléoniennes, insoupçonnée des meilleurs spécialistes du sujet: «Par caricatures napoléoniennes ou pro-napoléoniennes nous entendons toute pièce satirique servant la cause napoléonienne" (p. 13). Sachant que ce point de vue est loin d'être partagé dans la communauté des historiens et historiens de l'art, il le développe donc avec d'autant plus de vigueur, en arguant du fait que lorsque les caricatures de ces années 1814-1815, Cent-Jours inclus donc, attaquent les Bourbons, elles soutiennent de ce fait Napoléon, ce qui nous paraît un peu simplificateur. Durant cette brève période, les contemporains, bousculés par une actualité inquiétante et des changements de régime imprévisibles, pouvaient avoir critiqué le retour des Bourbons, sans pour autant saluer un Napoléon dont les dernières années du règne sont illustrées par des désastres militaires, parmi 
lesquels la cruelle campagne de France. Toutes les caricatures contre les Anglais, les Russes ou les Autrichiens - bref, contre les ennemis de la France - publiées auparavant seraient des soutiens à Napoléon, selon P. de Carbonnières.

Affirmation un peu radicale en fait, car il faudrait préalablement en savoir bien plus sur les auteurs et les diffuseurs (imprimeurs et libraires) de ces images. Or, comme à l'époque révolutionnaire, les éléments d'information manquent. Si le dépôt légal existe bel et bien, tout chercheur qui en a consulté les registres repère aisément les manques et les noms fautifs: la caricature sent toujours le soufre! L'observation matérielle des images conservées au musée Carnavalet a conduit l'auteur à y trouver les éléments d'une cohérence: un papier épais, légèrement gaufré, l'inscription du nom d'un marchandlibraire spécialisé dans la vente d'estampes populaires, "chez Martinet, rue du Coq à Paris" pour de nombreux documents publiés entre 1800 et 1806. Ce fonds, initialement collationné par Alfred de Liesville, l'un des premiers conservateurs du musée Carnavalet, lui a été légué à sa mort. Ici se joue la question irritante de la collection (comment a-t-elle été constituée?) et du collectionneur (quels étaient ses affects? Pourquoi ne trouve-t-on aucune caricature anti-napoléonienne ici? Pourquoi ne relève-t-on aucune caricature postérieure à 1806 ?). P. de Carbonnières soulève ce point de méthode mais, comme les autres chercheurs qui se sont penchés sur ce corpus bien particulier, il ne peut donner de réponse. Il faudrait sans doute réunir une équipe pour travailler sur les images figurant dans la presse illustrée entre 1814 et 1820 environ, les Nain jaune, Homme gris et autres Nain couleur de rose pour avancer dans la recherche. On ne trouve pas assez d'informations en ce sens dans Dominique Kalifa et alii (éd.), La civilisation du journal. Histoire culturelle et littéraire de la presse française au XIXe siècle, 2011.

Second problème: la définition parfois un peu extensive de la notion de "caricature». L'auteur nous invite à confronter une gravure de Bonnefoy, La machine infernale (1801) avec L'exclusif, caricature du même auteur, assurément très antijacobine (1797). Mais il ne mentionne pas que l'homme armé au bras vengeur et très menaçant de 1797 figure seul, au milieu de la planche, alors que l'homme de La machine infernale met clairement le feu au baril de poudre déposé sur la charrette de paille de la machine infernale, "rue Nicaise», comme il est écrit sur un mur. Nous avons là un dessin d'actualité, pour lequel le dessinateur a repris une figure employée précédemment. Peut-on alors tirer de ce rapprochement une conclusion aussi radicale, en affirmant que l'image démontre que le danger présenté ici, en 1801, pouvait encore être attribué aux «Jacobins» (terme générique convenu) et que, bien que Bonaparte ait rapidement eu connaissance que les royalistes étaient les auteurs de l'attentat de la rue Saint-Nicaise, il n'a pas cessé de pourchasser les Jacobins? Il conviendrait donc de poser la question de l'intentionnalité de ces caricatures de manière différente. En effet, en l'absence de volonté politique délibérée, attestée par des archives, comme le programme artistique de l'An II et la commande passée au peintre David par le comité de Salut public de réaliser des planches de propagande contre les Anglais, il ne faut jamais oublier que la force performative d'une image réside dans sa relation avec le spectateur. Une enquête pourrait être lancée grâce aux nombreux noms de libraires et d'éditeurs d'estampes cités, et grâce à toutes les informations précises apportées par ce livre. Il faut connaître les émetteurs, les usages sociaux et la réception d'une image avant de conclure sur son intentionnalité, cachée ou avérée. Un index des noms cités et une brève bibliographie complètent utilement l'ouvrage. 
Pierre Serna (Éd.), La politique du rire. Satires, caricatures et blasphèmes. $\mathrm{XVI}^{\mathrm{e}}$-XXIe siècle, Ceyzérieu, Champ Vallon, 2015, 261 p., ISBN 979-10-267-0073-9
Les assassinats perpétrés contre la rédaction du journal satirique Charlie Hebdo ont mis en avant de manière tragique les relations entre violence, politique et rire. Le massacre violait en effet l'un des fondements de la République laïque: une

"liberté absolue et de conscience» tolérant le droit de rire voire de blasphémer et celui - symétrique - de ne pas rire, sans pour autant recourir à la violence physique contre les personnes. Le présent ouvrage restitue la plupart des interventions données le 6 février 2015, un mois après ces tragiques événements. Précisons tout de suite que le titre et la plupart des auteurs appellent «rire» ce qui est plutôt du "comique", puisque le premier terme désigne un effet, et le second le dispositif (formel notamment) provoquant le rire ou le sourire.

Dans une substantielle introduction dédiée à la mémoire du regretté ChristianMarc Bosséno (qui n'en était pas dépourvu), le maître d'œuvre de cette initiative replace le comique dans ses rapports avec la violence et avec la politique, rapports déclinés ensuite par chacun des intervenants à l'aune du sujet qu'il aborde, et prenant pour point de départ la période moderne. En effet, pour Pierre Serna et bien d'autres auteurs, un "rire différent naît" entre la fin du XV et le début du XVI ${ }^{\mathrm{e}}$ siècle, qui accompagne «l'entrée en modernité du monde occidental»: valorisation progressive de la tolérance, conquête de la liberté d'expression, affirmation de l'autonomie du sujet, déprise de l'influence doctrinale du religieux et multiplication des supports "médiatiques" constitutifs d'un espace public.

La contribution d'I. Patin sur "Rabelais et ses papimanes" (adorateurs des textes produits par le pape) atteste qu'un jalon est posé, avec une attaque satirique frontale contre une Église coupable d'abus de pouvoir: comme A. Cabantous l'indique à propos des rapports entre le rire et le blasphème, on a là une parfaite illustration d'un «blasphémique» (l'objet du blasphème) portant sur ce qui, dans les croyances, est "proche de l'expérience humaine». L'auteur de Pantagruel convoque des formes antérieures variées (approche carnavalesque, farce médiévale et comédie fantastique), exploitant les déclinaisons multiples d'un comique mobilisé contre une sorte de ligue anti-rire qui, depuis la faculté de théologie de Paris, milite obstinément pour l'interdiction de la vente de son ouvrage, en dépit des privilèges royaux accordés. Mais l'arrière-plan de la satire rabelaisienne - que révèlent sa mise en contexte et les relations de l'auteur avec l'entourage du roi de France (via du Bellay) - est aussi politique. Elle évolue sur fond de conflit avec Jules III, de la volonté d'Henri II de mettre fin aux transferts d'argent vers Rome, du rapprochement avec Soliman, d'une menace royale de la tenue d'un concile en France et du refus d'une réouverture de celui de Trente. Tel est l'arrière-plan de la querelle entre "Papimanes» et "Papefigues", les seconds persécutés par les premiers, ce qui fait écho aux violences exercées au même moment contre les Vaudois.

Le renversement de perspective par rapport au Moyen Âge est plus ambivalent dans le cas des rapports entre rire et prédication. Divers travaux (par exemple J. Horowitz, S. Menache, L'humour en chaire. Le rire dans l'Église médiévale, 1994) avaient déjà montré qu'au Moyen Âge la parole religieuse pouvait utiliser les ressources pédagogiques du comique; mais des sermons burlesques virent aussi le jour, attirant la parole religieuse dans le périmètre du risible. Dans le fil de cette dernière tradition, I. Brian s'intéresse aux sermons satiriques du XVIII ${ }^{\mathrm{e}}$ siècle, répertoriés 
par exemple dans le Predicatoriana de l'érudit Gabriel Peignot (1841). Le "comique en chaire" présente plusieurs niveaux et de multiples usages du rire. Il y a d'abord la dimension normative du comique pour se rire du prédicateur (mise en scène d'un clerc souvent novice, maladroit et soporifique); dans un deuxième temps se développe une satire du prédicateur et de son public, la fonction offensive du rire servant pour une attaque à peine voilée des prédicateurs méthodistes britanniques. Enfin, un comique plus radical encore se déploie, qui met directement en cause le discours religieux d'autorité : le sermon du curé de Colignac (1736) s'en prend parfois au dogme lui-même, le dynamitant sur le fond au moment où Voltaire commence à prendre la main. S'esquisse alors un glissement du «blasphémique» d'un risible (les topoï de l'anticléricalisme) évoqué plus haut vers un autre - une dérision touchant aux Écritures et aux dogmes.

J.-M. Le Gall montre que la dilatation du périmètre du «risible» observable à la Renaissance accompagne une reviviscence de genres comiques en vogue sous l'Antiquité romaine (rhétorique cicéronienne, comédies et farces d'Horace ou Juvénal) et mis en berne au Moyen Âge. La première moitié du XVI ${ }^{\mathrm{e}}$ siècle revisite donc Démocrite, ce philosophe qui riait de tout à tout moment, et elle privilégie un comique pédagogique à la fois utile (il corrige la crédulité) et plaisant (il vaut mieux que l'invective). Les guerres de Religion favorisent un comique inspiré du rire de supériorité de Cicéron ou de Quintilien, dans un but clairement subversif et agressif: il sert une violence purificatrice et/ou pédagogique à des fins d'outrage et de désacralisation (à l'égard des rites catholiques). Le degré d'agressivité de ce rire est tel que bientôt l'État doit intervenir (édit de janvier 1562) pour réprimer injures et invectives. On encourage alors la mise en veilleuse des sociétés joyeuses, indices d'une sociabilité du rire en plein essor, à l'instar des "connards» de Rouen. De leur côté, les élites urbaines financent les troupes théâtrales à but purement distractif et favorisent l'envoi des jeunes dans les collèges jésuites largement financés par les municipalités. Enfin, au XVII ${ }^{\mathrm{e}}$ siècle, la diffusion d'une mystique venue d'Espagne impose une démarcation entre la joie (autorisée) et le rire, qui l'est moins. Les misères du temps et leur cortège de violences inspirent enfin un rire de consolation, de résistance ou d'exorcisation. Comme plus haut, la taxinomie des fonctions du rire et ses déclinaisons multiples se vérifient et se combinent.

La question du rapport entre le rire et la violence est au cœur de la contribution d'H. Drévillon sur le rire dans le monde militaire à l'époque moderne. Dans un groupe défini par l'usage de la violence jusqu'au sein même de l'institution (sanctions et duels), le comique est d'abord cathartique, lui qui aide à affronter les hasards de la guerre et met la violence à distance par le verbe. Mais il peut aussi être un rire de dérèglement dans les situations les plus extrêmes (les victimes animalisées voient leur humanité effacée). H. Drévillon s'attache également à l'une des spécialités de ce "rire du sergent" si éloigné du rire aristocratique : la rodomontade, présente dans les mémoires du chevalier de Quincy, théorisée par Brantôme. Les déconvenues cocasses de matamores célèbres ou de célébrités "matamorisées》- comme Soubise recherchant les vestiges de ses troupes à la lanterne après le désastre de Rossbach - montrent qu'il est possible de se moquer d'un prince de haut rang pour mieux s'interdire de rire de la nation, malmenée sur les champs de bataille mais déjà sacralisée en France. On voit par là comment le «blasphémique» se dilate des croyances religieuses vers d'autres sphères (la nation et plus tard les droits de l'Homme, la liberté, la République). 
Dans une communication à cette journée d'études (non publiée mais qu'il importe d'évoquer), A. Wegener a étudié la sociabilité du rire, via la tradition des toasts portés au cours du XVIII ${ }^{\mathrm{e}}$ siècle par les "Spitz-loups» (patriotes hollandais) contre les orangistes (partisans du stathouder des Pays-Bas), et réciproquement. De part et d'autre, le rituel des toasts se rode - les premiers sont sérieux, les suivants de moins en moins - et, à mesure que l'humour se généralise, les jeux à boire se sophistiquent et les toasts gravés sur verre se développent: ici, un Spitz-loup urine sur le tronc d'un oranger; là, des devises du camp adverse sont détournées. $\mathrm{Au}$ besoin, la satire ne recule devant aucune allusion sexuelle: elle montre volontiers le stathouder Guillaume V en sanglier priapique, et sert de plus en plus ouvertement la propagande politique. Les républicains hollandais, à l'instar de leurs prédécesseurs anglais du XVII ${ }^{\mathrm{e}}$ siècle, sapent donc la sacralité du souverain bien avant leurs homologues français. Le comique, en même temps qu'il opère une mise à distance de sa cible, soude une communauté de rieurs partageant les mêmes codes et convictions.

La socialisation dans et par le comique se retrouve jusque chez ces normaliens étudiés par P. Verschueren dans la période 1945-1971 : s'agit-il d'un humour fermé sur lui-même, et quelles peuvent en être les significations? Rire de caste, de délimitation et de consolidation d'un corps, l'humour made in ENS l'est certainement, et l'initiation commence lors des oraux du concours, quand les vrais candidats se présentent à de faux jurys, ou de faux candidats à de vrais jurys. L'auteur luimême perpétue la tradition de ses spirituels prédécesseurs, puisqu'il nous gratifie en toute fin d'article d'un khânular crypté, en glissant une expression sans grand rapport avec sa démonstration. On soulignera que l'esprit de corps peut aller très loin: non seulement aux dépens des élèves-officiers de l'X, en pimentant l'humour d'un antimilitarisme croissant, mais aussi à l'égard des normaliennes, sur fond de misogynie et d'amertume (car deux ans de service national retardent alors les carrières masculines). C'est également un rire qui s'amuse des pesanteurs universitaires et du mandarinat en vigueur, pour mieux asseoir symboliquement la domination des normaliens dans un champ où ils excellent. Mais c'est aussi, pour les élèves, un comique à connotation politique, un rire de "doublement dominés» : au sein de l'institution (en raison du poids des communistes, puis d'une extrême gauche, surtout maoïste et pisse-vinaigre), comme dans un pays où le gaullisme revient au pouvoir avec un large assentiment de l'opinion. Pour marquer la prise de fonction du «plus illustre des Français", un squelette de girafe arborant l'uniforme et juché sur une cantine roulante de l'ENS fera le trajet de la rue d'Ulm jusqu'aux Champs Élysées! P. Verschueren examine aussi l'humour prisé et pratiqué par des enseignants qui ont le même profil que leurs élèves; la perspective est alors plus axée sur la sociabilité entre collègues et la recherche d'une étroite coordination entre littéraires et scientifiques. Mais l'exemple des écrits comiques du physicien Yves Rocard montre aussi un homo comicus en perpétuelle revendication de crédits pour son laboratoire et de débouchés pour des ouailles qu'il veut orienter vers la recherche et non vers le lycée, sans passer par une agrégation de physique largement brocardée.

Presqu'un siècle plus tôt, le travail que leur illustre congénère philosophe consacra au rire couronnait une période d'essor du comique en le plaçant comme sujet d'étude à part entière. L'abondance de la littérature consacrée au rire et consultée par Henri Bergson atteste cette importance. A. de Baecque montre que dans ce moment du "rire 1900", le comique se déploie sur toutes sortes de registres: de la «gauloiserie» - rire collectif et ciment affectif pour la nation - au rire normatif qui 
châtie les mœurs et impose un comportement, en passant par un comique vecteur de civilisation républicaine. Il emprunte des formes diverses, de la caricature aux premiers moments de cinéma burlesque: de ce point de vue, on est frappé par la correspondance entre l'Onésime filmé par Max Linder et l'approche bergsonienne du rire qui introduit le dérèglement dans une vie humaine au comportement dicté par la mécanique.

Dans une contribution portant sur le temps présent en Égypte - les manifestations "Erhal!» ("Dégage!») qui ont conduit à la chute de Moubarak - L. Vuilliaume montre comment le street art combine efficacement humour et révolution, dans un mouvement de libération, de création et de résistance au pouvoir en place.

L. Bihl étudie "l'outrage aux bonnes mœurs» du point de vue d'un État libéral qui, dans la France des débuts de la III République, est confronté à la profusion d'images satiriques et tente un délicat effort de démarcation entre peurs de natures différentes. La question est ici de savoir si, outre ces «images obscènes" visées par diverses lois s'échelonnant du 2 août 1882 au 7 avril 1908, ce ne sont pas aussi les images de la propagande d'opposition qui sont ciblées. De fait, jusqu'en 1894, le ministère public engage des poursuites pour venir à bout des titres de satire politique (Le Courrier français boulangiste) et l'on en arrive à chicaner pour savoir si la nudité de Marianne est ou non aussi voluptueuse qu'un simple déshabillé. Mais le volume de production de la presse prend vite de court la préfecture et le Parquet, qui frappent souvent de manière erratique: les non-lieux en cascade sont autant de victoires pour des dessinateurs enclins à prendre à témoin l'opinion, et d'autant plus de publicité gratuite pour les publications. Dès lors, il faudra à l'État d'autres motifs que l'obscénité pour réprimer le dessin satirique en matière politique.

Cette dernière contribution ouvre une piste de recherche prometteuse pour toute étude située au carrefour du rire, de la violence et du blasphème. La question est du reste soulevée en introduction par P. Serna et en conclusion par A. Cabantous: quelle est et comment évolue la perception-réception du comique et de ses utilisateurs par ceux qui se sentent visés et agressés par le rire et fondés à demander réparation? Cet angle d'attaque est au moins aussi important que l'histoire déjà bien renseignée des mécanismes, des cibles et des destinataires du comique. Il lui est même complémentaire, si l'on considère que le public du comique ne saurait se limiter au périmètre des rieurs. Ce champ des perceptions, des représentations et des réponses au rire transgressif peut-il rester en friche? L. Bihl montre en tout cas que, du point de vue des pouvoirs publics, la définition de «l'obscénité» comme motif de répression est assez plastique et peu opératoire quand elle s'applique à la satire politique. A. Cabantous estime qu'en même temps que le comique et la notion de blasphème s'élargissent et gagnent en plasticité, le regard sur le blasphémateur et le profil de ce dernier évoluent: il fut d'abord celui qui attaque les croyances, puis un mauvais croyant et enfin un incroyant (de «l'esprit fort» libertin aux déchristianisateurs de l'An II). Il en va de même pour les réponses au blasphème: manifestement, le "silence éloquent qui déshonore celui qui a lancé le défi" (p. 254) n’est plus de mise aujourd'hui, dans des milieux très éloignés du processus de "civilisation des mœurs». 


\section{Elisa Marazzi, \\ Libri per diventare italiani. L'editoria per la scuola a Milano nel secondo Ottocento, \\ Milan, Franco Angeli, 2014, 331 p., ISBN 978-88-917-0804-5}

Pour étudier la nationalisation des Italiens dans la deuxième moitié du XIX ${ }^{e}$ siècle, Elisa Marazzi a choisi une approche fondée sur l'histoire des maisons d'édition milanaises spécialisées dans le manuel scolaire et le livre d'éducation, à une

époque où ces ouvrages ont été considérés comme des instruments irremplaçables pour créer le sentiment d'appartenance nationale et instruire la population. En reconstituant le panorama typographique et éditorial de la capitale lombarde, elle retrace le développement des politiques culturelles et des stratégies commerciales mises en œuvre par les acteurs principaux de cette période, qui constituent progressivement un nouveau pôle éditorial dans la géographie du livre d'école italien. Ils prennent place à côté des éditeurs de Turin et Florence, les deux centres traditionnels où la production pédagogique s'était développée dès la première moitié du siècle, à la faveur de l'intérêt des élites piémontaises et toscanes pour l'instruction populaire, tandis qu'à Milan, sous la Restauration, l'Imprimerie impériale autrichienne avait conservé le monopole de l'impression des livres d'école, sélectionnés par une commission à Vienne.

Ce n'est qu'après l'Unité qu'un groupe de libraires-imprimeurs dans la capitale lombarde se consacre à cette production de masse, facile à imprimer et à écouler. Parmi eux, E. Marazzi suit minutieusement la trajectoire des maisons d'Antonio Vallardi, Enrico Trevisini, Giacomo Agnelli et Paolo Carrara. Le premier s'était spécialisé dans la cartographie, ainsi que dans différents supports pour l'enseignement "objectif» (comme les tableaux scolaires, les tables de nomenclature, ou les objets de la méthode fröbelienne), avant de se tourner vers les livres de lecture et les ouvrages didactiques, alors que le second a fait d'emblée le choix du secteur scolaire pour développer son entreprise et ne diversifie que par la suite sa production, en ouvrant des collections de lectures populaires. Les deux derniers appartiennent à une sphère plus conservatrice. Agnelli, traditionnellement tourné vers le livre religieux et dévotionnel, se lance dans l'impression d'ouvrages de lectures éducatives pour le peuple et pour l'enfance; enfin Carrara (qui n'a jamais d'imprimerie en propre) s'adonne à une production hétéroclite où les livres d'école et d'éducation populaire côtoient la littérature «manzonienne» et la littérature de jeunesse traduite, notamment française. C'est par le biais de ces traductions qu'il reviendra à cet éditeur-libraire sans spécialisation bien affirmée «d'introdurre nella letteratura per l'infanzia italiana esempi di racconti dove il romanzesco e l'avventuroso sopravanzavano le componenti edificanti o didattiche" (p. 173). La même insuffisance de stratégie éditoriale se retrouve d'ailleurs dans les "collections» ouvertes par tous ces éditeurs milanais, qui les multiplient en leur donnant des intitulés similaires (Bibliotechina per il popolo, Piccola Biblioteca Popolare di educazione e ricreazione, Biblioteca istruttiva, Biblioteca per le famiglie, Nuova Biblioteca educativa ed istruttiva) et en réunissant des œuvres soumises aux visées moralisatrices et didactiques du projet d'éducation des masses soutenu par la classe dirigeante après l'Unité. E. Marazzi démontre que toutes ces collections sont en réalité des répertoires indifférenciés sur le fond, destinés avant tout à présenter la production de manière classée: un expédient publicitaire comme un autre, qui cache l'absence de tout véritable projet éditorial, et regroupe sans les sélectionner des textes relevant de genres et de destinataires différents. Ces mêmes objectifs, idéologiques et commerciaux, président également aux collections des "livres de prix" (une tradition bien enracinée dans les pratiques scolaires) qui, moyennant 
une meilleure reliure, permettaient d'écouler les invendus en les présentant comme des livres de loisir.

Par la suite Agnelli, Carrara et Trevisini restent enfermés dans leur logique conservatrice, et finissent par disparaître; seul Vallardi subsiste, en se recentrant sur le secteur scolaire (notamment dans le secondaire). Le renouveau vient en revanche des éditeurs milanais qui, en s'adressant aux enfants d'un public bourgeois (comme Treves), ou bien en diffusant une production de masse qui privilégie le romanesque et l'exotique (comme Sonzogno), savent répondre à la fin du XIX ${ }^{\mathrm{e}}$ siècle aux nouvelles demandes du public.

Mariella CoLIN Université de Caen-Normandie

\author{
MAURIZIO RIDOLFI, \\ La politica dei colori. Emozioni e passioni nella \\ storia d'Italia dal Risorgimento al ventennio fascista, \\ Florence, Le Monnier, 2014, 323 p., \\ ISBN 978-88-00-74451-5 \\ Italia a colori. Storia delle passioni politiche \\ dalla caduta del fascismo ad oggi, \\ Florence, Le Monnier, 2015, 336 p., \\ ISBN 978-88-00-74553-6
}

Spécialiste reconnu de l'histoire politique de l'Italie de la fin du XIX ${ }^{\mathrm{e}}$ siècle et du Xx ${ }^{\mathrm{e}}$, Maurizio Ridolfi s'attache depuis quelques années à donner un éclairage nouveau à son champ d'étude, par des approches plus ouvertes à l'histoire culturelle, à l'histoire des émotions ou à l'anthropologie. C'est le cas ici, avec ces deux livres qui abordent l'histoire de l'Italie contemporaine sous l'angle des couleurs. Se réclamant de Maurice Agulhon dans sa volonté d'éclairer les vecteurs de la politisation, $M$. Ridolfi fait l'hypothèse que les couleurs jouent un rôle central dans le processus d'apprentissage politique des Italiens, depuis le Risorgimento jusqu'à nos jours. Par ce prisme, il entend retracer l'histoire des "passions et des émotions politiques» italiennes, s'insérant dans un vaste champ d'étude d'«histoire culturelle du politique».

Ce projet, d'une ampleur certaine, laisse nécessairement certains aspects de côté. On regrettera par exemple que l'étude des émotions politiques, pourtant annoncée par le sous-titre du premier ouvrage, ne soit le plus souvent qu'effleurée. Cependant, au fil de ces près de 700 pages d'une agréable lecture, $M$. Ridolfi offre un panorama convaincant des mutations de la société italienne, des différentes cultures politiques qui y cohabitent et de leurs multiples recompositions, ainsi que des représentations qu'elles suscitent. Très riches en notes, les deux ouvrages sont par ailleurs une mine de références sur toute la période, témoignant d'un travail bibliographique de grande envergure. On notera aussi l'astucieux système de renvoi au site internet de l'éditeur, qui permet de consulter les nombreux documents iconographiques évoqués, en sus du cahier central illustré déjà nourri, ce qui autorise la multiplication des exemples.

L'étude sur la longue durée permet de mettre en évidence la grande permanence de certaines problématiques: ainsi des débats qui entourent le drapeau tricolore italien. Symbole national jamais totalement partagé, il peine à représenter l'ensemble des Italiens: comme étendard de l'unité, il est d'abord vilipendé par l'Église; objet disputé entre fascistes et antifascistes, puis suspect de nationalisme dans les années d'aprèsguerre, il est de nouveau rejeté à la fin du $\mathrm{XX}^{\mathrm{e}}$ siècle par les tenants d'une autonomie voire d'une sécession du nord de la péninsule. Malgré cela, il demeure perpétuellement au cœur de la vie politique, faisant l'objet de tentatives d'appropriation concurrentes. M. Ridolfi montre parfaitement comment les partis de gauche de l'Italie républicaine 
cherchent à le combiner au traditionnel rouge des partis ouvriers, afin de se poser en partis nationaux: si les symboles à destination des militants s'appuient quasi exclusivement sur le rouge, la communication externe de ces formations privilégie les emblèmes nationaux. Ce processus d'appropriation du drapeau tricolore est aussi observable à une époque plus récente, de la création du parti de Silvio Berlusconi au milieu des années 1990 - Forza Italia - jusqu'au plus récent Parti démocrate, lointain héritier du Parti communiste qui, pour la première fois, renonce à la prédominance du rouge au profit du drapeau national. La volonté de rassembler l'ensemble du corps social dans le programme de ces partis montre ainsi une évolution par rapport aux premières années de la République italienne, où les antagonismes politiques et sociaux sont revendiqués, notamment grâce aux couleurs.

C'est l'un des intérêts de ces livres que de montrer combien les représentations chromatiques ont contribué à façonner la figure de l'«ennemi intérieur", omniprésent dans la rhétorique politique du $\mathrm{XX}^{\mathrm{e}}$ siècle. Parce qu'elles permettent de construire une vision du monde ordonnée et binaire, les couleurs ont joué dans la construction et la représentation des antagonismes politiques et sociaux un rôle fondamental qui atteint son apogée dans la Guerre froide. M. Ridolfi montre ainsi à quel point le rouge est une couleur clivante, à la fois motif d'orgueil pour les partis de gauche et moyen de disqualification quand il est utilisé par la démocratie chrétienne qui l'associe à la violence et au parti de l'étranger.

Ces deux livres se distinguent aussi par la volonté d'étudier la question chromatique à différentes échelles. Le premier offre ainsi d'intéressants développements sur la circulation des couleurs et des symboles en Europe au XIX $\mathrm{X}^{\mathrm{e}}$ siècle, depuis les thèmes liés à la Révolution française jusqu'aux couleurs des mouvements ouvriers. Ces derniers s'échangent des symboles, notamment grâce à la diffusion des manifestations du $1^{\mathrm{er}}$ mai: par exemple, les socialistes italiens commencent, à la fin du siècle, à arborer l'œillet et la rose rouges qui viennent respectivement d'Autriche et d'Allemagne. Le second ouvrage cherche aussi à lancer des pistes de recherche quant à l'étude des couleurs de la politique à l'échelle locale, pour mettre en évidence d'éventuelles variations par rapport aux chromatismes utilisés par les partis nationaux; il s'agit encore largement d'une ébauche mais qui semble porteuse de pistes fécondes.

Enfin, c'est aussi à travers les couleurs que l'auteur s'intéresse à l'accentuation du caractère spectaculaire de la politique italienne au cours du $\mathrm{XX}^{\mathrm{e}}$ siècle. Reprenant les nombreux travaux consacrés à la communication politique de Mussolini, M. Ridolfi montre que la tendance à faire de la politique un spectacle ne disparaît pas avec l'avènement de la république: à partir de l'étude de la mise en scène des funérailles des grands dirigeants communistes, il souligne que ces cérémonies tendent à abolir la frontière entre public et privé, et gagnent en puissance médiatique. Ce phénomène, accentué par Bettino Craxi et ses meetings inspirés de la politique étasunienne dans les années 1980, trouve son apogée avec l'entrée en politique de Silvio Berlusconi, qui achève cette fusion entre médias de masse, divertissement et vie politique.

C'est donc un travail de synthèse réussi qu'offre $M$. Ridolfi: parcourant l'histoire de la société italienne, il dévoile le rapport complexe qu'entretiennent la culture de masse, les couleurs et la vie politique, rappelant la multiplicité des vecteurs de la politisation et réaffirmant le lien étroit qui existe entre la représentation des phénomènes politiques et leur réception. 


\begin{abstract}
Sergio Luzzatto, Comment l'histoire de la Résistance Partigia. Primo Levi, la Résistance et la mémoire, Paris, Gallimard, 2016, 457 p., ISBN 978-2-07-014388-7 peut-elle encore nous atteindre et nous parler? Pour Sergio Luzzatto, il suffit de l'observer à son "niveau zéro" (p. 26). Publié en Italie en 2013, ce livre est traduit avec un sous-titre qui situe l'évé-
\end{abstract} nement entre la figure de l'acteur-témoin et la représentation de ce passé dans la mémoire. Du fait vécu à sa transmission, l'enquête de S. Luzzatto propose en effet de réinterroger un héritage à l'aune de plusieurs expériences historiques concrètes et individuelles, dont les destins finissent par se croiser et se renverser entre les années 1940 et 1950. Sous sa plume, l'épopée devient l'histoire d'un «bien inestimable», en même temps que celle d'un "mal insondable».

Considéré comme un survivant de la Shoah davantage que de la Résistance, l'auteur de Si c'est un homme occupe logiquement dans cette histoire un «second rôle» (p. 27). Ce sont pourtant ses écrits, narratifs et poétiques, qui forment autant de témoignages historiques et de sources où $\mathrm{S}$. Luzzatto décèle, de manière souvent masquée ou implicite, des représentations dissonantes et en contradiction avec une représentation mythifiée de ce passé. C'est ainsi qu'il se lance sur la piste du "vilain secret» de Primo Levi, évoqué dans douze lignes de la nouvelle "Or», publiée pour la première fois en 1973 puis intégrée dans Le système périodique (1975). Un assassinat sauvage de partisans par d'autres partisans, un épisode de la vie des «rebelles» du val d'Aoste, que l'historien tente de reconstituer afin d'éclairer l'histoire de la "guerre civile» italienne (p. 24) et d'illustrer les premiers temps d'un engagement partagé «entre banditisme et aventures picaresques" (p. 89). Autour d'une révélation embarrassante, laissée de côté ou ignorée, S. Luzzatto déroule des parcours politiques, des itinéraires heurtés, hésitants, complexes, où l'engagement apparaît moins comme la conséquence d'une conviction morale que comme une «dernière chance à la roulette de la vie» (p. 83).

L'expérience de Primo Levi permet d'illustrer ce constat: le parcours du Piémontais et de ses proches, retirés dans le val d'Aoste à l'automne 1943 afin de fuir l'envahisseur allemand, est l'histoire d'un partisan malgré lui, dans un contexte où la Résistance restait à «inventer» (p. 59). Les quatre premiers chapitres reconstituent en quelques étapes décisives la vie de "rebelle» de Primo Levi, ces trois mois ponctués par une arrestation, lors de la "première rafle de l'histoire de la Résistance». Cette expérience, malgré sa brièveté, permet à l'auteur de faire ressortir les problèmes qui se posent alors pour tous, bien que dans des termes différents, au lendemain de l'armistice du 8 septembre. Un «juif en fuite» croise ainsi la route de partisans turinois, auprès de qui il finit par trouver refuge. Ces partisans finissent par se lier avec d'autres jeunes hommes, restés volontairement à l'écart de l'autorité du Comité de libération local, et soudainement "gagnés par l'ivresse de leur nouvelle condition, la sensation grisante de n’avoir ni toit ni loi» (p. 88). Les mêmes rebelles sont espionnés par un dernier personnage qui devait quant à lui répondre aux ordres du préfet d'Aoste, et qui était parvenu à infiltrer leur bande. Cette histoire de la Résistance se concentre ainsi dans un espace d'à peine quinze kilomètres à l'est d'Aoste et est centrée sur quelques personnalités dont les intentions et les motifs de leur "enrôlement" dans l'un ou l'autre camp sont patiemment sondés et reconstitués. Les gestes, les choix, les décisions qui remplissent ce passé se sont chargés ultérieurement d'un sens et d'une intensité symboliques particuliers, à la faveur des témoignages qui honoraient et voulaient éduquer en même temps qu'ils attestaient. 
S. Luzzatto multiplie les sources, tente de combler parfois leur absence par l'exploration physique des lieux, mettant à profit les enseignements de l'historien anglais Richard Cobb. Afin de pouvoir reconstruire et interpréter ce qui forme «le cœur des ténèbres de cette histoire" (p. 97), le "vilain secret" de Levi et des autres partisans, l'auteur confronte les témoignages littéraires aux procès-verbaux des interrogatoires tenus dans la caserne de la Milice locale, en passant par les entretiens avec les proches et les parents, voire des protagonistes encore en vie. Ce sont finalement des mémoires qui se font écho, se contredisent et ouvrent des questionnements, que les investigations de l'historien poursuivent, approfondissent, au risque de bouleverser et d'altérer "la vérité d'un sacrifice» (p. 332). S. Luzzatto évoque «la limite morale» de son travail intellectuel qui, par l'attention qu'il porte à des événements considérés comme "mineurs", avive des douleurs intimes qu'il ne peut «réparer», autant qu'il remet en question les grands récits collectifs.

La deuxième partie de l'ouvrage, également articulée en quatre chapitres, poursuit la destinée des différents protagonistes, les "héros", les condamnés et les morts. Dans les dix années qui suivent immédiatement la guerre et qui sont analysées ici, le rôle de la mémoire et la manière dont elle prend forme, entre quête de justesse et désir de justice, sont centraux. La contemporanéité de certains événements, comme le procès du représentant antisémite de Salò et le retour du «juif rescapé», pourrait suffire à démontrer, comme le souligne l'auteur, que le destin «se charge d'une morale [...] comme si l'histoire était littérature» (p. 199). C'est davantage, pourtant, par la voie d'une remise en forme du passé, à travers le témoignage versé à un procès, que le récit ouvre sur une réparation. Le mouchard Edilio Cagni et le préfet Cesare Augusto Carnazzi sont condamnés à mort en 1946. La suite de leur parcours, entre révisions en appel, grâces et collaboration avec les services secrets étatsuniens permet, malgré tout, d'illustrer la dilution d'une mémoire de la Résistance, dans le climat historique de la Guerre froide naissante, que s'efforce de restituer S. Luzzatto. En 1950, l'agent trouble Cagni est définitivement libéré. À rebours des critiques des intellectuels et des figures "morales» de l'époque, qui dénonçaient une culture de la "désistance», cette mesure de clémence est mise en balance avec les décisions de justice prises dans l'immédiat après-guerre et qui n'étaient donc pas moins redevables d'un contexte travestissant la justice administrée par les cours d'assises extraordinaires, "aucunement indépendante ni innocente» (p. 285).

L'histoire de la Résistance retracée par S. Luzzatto a donc moins «la séduction simple des contrastes» que «la vérité compliquée des dégradés" (p. 30), comme il l'annonce dès l'introduction. Très critiqué lors de sa sortie, en Italie, l'ouvrage est augmenté, dans son édition française, d'une postface inédite dans laquelle $S$. Luzzatto propose d'interpréter l'origine des critiques qui lui ont été opposées. Ces reproches sont ainsi évalués au regard de l'histoire commune qui rapproche ceux qui en sont les auteurs, à savoir une participation aux luttes politiques des années 1970, dans les rangs de l'extrême gauche extraparlementaire. Évoquant plus particulièrement la singularité de l'héritage culturel et mémoriel des principaux acteurs piémontais du mouvement Lotta continua, l'auteur retrace le parcours idéologique de ces fils d'anciens partisans qui ont progressivement réévalué l'histoire du combat mené par leurs pères, jusqu'à nourrir aujourd'hui une profonde nostalgie envers une histoire vécue et ressentie comme "parfaite». Pour comprendre les ressorts idéologiques et mémoriels des interprétations critiques qu'a suscitées son enquête, l'auteur se propose ainsi de prolonger son récit, au-delà des années 1950, afin de témoigner de "l'effacement de la Résistance comme expérience vécue» et de la «relance de la Résistance comme expérience imaginée». 
Ce prolongement est l'occasion de revenir sur le parcours de Primo Levi, entre les années 1960 et 1970, sur la représentation de son "devoir civique», et la manière dont il l'a exercé dans la vie politique et intellectuelle italienne. L'auteur poursuit ainsi la réflexion amorcée dans les pages qui précèdent, autour de la figure du "témoin moral». Le principal intérêt de l'ouvrage est effectivement d'interroger le statut d'un témoignage extrêmement varié dans ses formes, ses usages et ses finalités. L'entreprise de l'auteur ne consiste pas simplement à opérer une critique de la violence "partisane", afin d'en renverser la figure héritée et, finalement, de banaliser la littérature de témoignage. La critique historique de $S$. Luzzatto tente davantage d'interpréter la construction de l'«ethos» du témoin: «le problème historique de Levi témoin gagne à être traité en même temps que le problème historique du témoin Levi» (p. 222). Les lignes du «vilain secret» ne sont pas portées au dossier de l'historien afin d'incriminer le témoin mais permettent de comprendre le malaise du récitant, tenant un rôle qu'il assume difficilement, car étant ou se sentant «foncièrement différent du personnage [qu'il] représente" (Primo Levi, 1966).

Thibault GUICHARD

IHTP (UMR 8244), Université Paris 8

\begin{tabular}{|c|c|}
\hline $\begin{array}{r}\text { SÉBAstien Ledoux, } \\
\text { Le devoir de mémoire: } \\
\text { une formule et son histoire, } \\
\text { ris, CNRS-Éditions, 2016, 367 p., } \\
\text { ISBN 978-2-271-08800-0 }\end{array}$ & $\begin{array}{l}\text { Sébastien Ledoux présente ici } \\
\text { ouvrage dense issu de sa thèse. Il s'in } \\
\text { resse à un sujet souvent brûlant: ider } \\
\text { fier les usages politiques de la notion } \\
\text { "devoir de mémoire" en France en } \\
\text { les années } 1970 \text { et } 2000 \text {. Ce devoir }\end{array}$ \\
\hline
\end{tabular}

mobilisé par des acteurs de plus en plus nombreux, issus des mondes académique, politique ou associatif. Pourtant, ce «récit à prétention scientifique associant l'origine du terme à un [...] fait historique» a «progressivement évolué vers un savoir relevant du sens commun", sans faire l'objet d'une monographie (p. 17). C'est aujourd'hui chose faite.

L'auteur conjugue deux dimensions. La première est une analyse sémantique qui revient sur les origines historiques de l'expression "devoir de mémoire». Dans les années 1980, le mot mémoire (lui-même construit et reconstruit) est régulièrement adossé à la notion de devoir, ajoutant une charge morale d'abord associée au génocide des juifs en France puis élargie à d'autres histoires. Le devoir de mémoire sort du champ universitaire et est utilisé par des acteurs institutionnels (ministres, commissions d'études, etc.) qui, au gré des débats publics, le transforment en un positionnement de l'État face au négationnisme, en une politique institutionnelle du passé (commémorations) et en "une formule consacrée». La seconde dimension est une histoire sociale qui recontextualise le devoir de mémoire dans l'histoire d'une France confrontée, à partir des années 1970, à de nouvelles formes d'identités (régionales, communautaires) dont les porteurs souhaitent une meilleure visibilité dans l'espace public. S. Ledoux dévoile la flexibilité d'une expression mobilisée tant par des institutions, le public et les médias pour évoquer les traces d'évènements très divers (la rafle du Vel d'Hiv', la guerre d'Algérie ou la traite transatlantique). Cette approche double permet de dépasser la définition du devoir de mémoire comme la nécessaire résurgence d'un passé oublié. 
Dans une première partie, l'auteur propose une généalogie du devoir de mémoire, pour en saisir l'origine, au-delà de la simple référence à Primo Levi. Il en historicise "l'identité narrative» (p. 16) et découvre les mécanismes sociaux et politiques qui ont conduit à son émergence dans le débat public. À partir des années 1970, cette notion est travaillée par des historiens qui tentent d'en comprendre la complexité et les limites probables. La médiatisation de certains d'entre eux contribue à la populariser, en lui donnant le sceau d'une scientificité légitimant ses usages sociaux et populaires. Son emploi scientifique l'a stabilisée en définissant la mémoire non comme la somme de traces d'un passé exhumé mais comme une "catégorie d'action du présent sur le présent" (J.Davalon, cité p. 33). Dans les années 1980, des associations de déportés commencent à utiliser le devoir de mémoire pour qualifier les récits de leur expérience des camps, du génocide des juifs ainsi que la chasse aux criminels nazis. Le devoir de mémoire devient une conscience historique destinée à exercer une justice réparatrice rendue possible par la notion d'imprescriptibilité du crime contre l'humanité. Il est alors une lutte contre l'amnésie des peuples et des États mais aussi un référent de la construction d'une identité juive post-génocidaire. C'est à cette période que l'expression entre dans le vocabulaire politique, à la suite notamment d'attaques antisémites (dont la profanation de Carpentras, 1980). La mémoire acquiert une valeur politique qui ne la quittera plus. Davantage, les gouvernements successifs s'engagent dans une "politique de mémoire». En effet, dès 1981, non seulement François Mitterrand et son gouvernement l'utilisent comme une catégorie d'action politique, grâce à laquelle des stratégies et des lois sont élaborées, mais l'État devient le dépositaire d'une "mémoire collective», comprise comme une somme d'événements historiques à partager dans la communauté nationale. Il est le garant et le passeur d'une mémoire prise comme le socle d'une identité commune. S. Ledoux montre avec précision comment les différentes structures ministérielles, comme la "Mission permanente pour les commémorations et l'information historique", inventent des lieux de mémoire (nécropoles, champs de bataille) et des héros afin de modeler cette mémoire nationale. L'étude sémantique s'avère très utile car elle permet à l'auteur de déconstruire toutes les expressions associées au devoir de mémoire: lieux de mémoire, héros, mémoire collective, mémoire nationale, etc.

Rapidement, d'autres acteurs s'approprient cette définition pour qualifier les «histoires à soi» (selon le titre de l'ouvrage d'Alban Bensa et Daniel Fabre en 2001) de groupes sociaux désireux de représenter leur mémoire à partir d'un local, voire d'un below. Dans les troisième et quatrième parties du livre, l'auteur analyse comment le devoir de mémoire est devenu une "formule» du langage politique qui encadre «un régime d'actions» justifié par "un modèle de justice orienté vers le bien commun et prétendant à une validité universelle» (p. 143). Il montre comment ce qui tient d'abord d'une formule rhétorique et politique qualifiant des actions ponctuelles de commémoration, devient un "cadre référentiel» : le devoir de mémoire initie de nouvelles formes d'actions, mobilise de nouveaux acteurs mais s'insère également dans des "grammaires" existantes (lutte contre l'oubli, occultation de la vérité, transmission aux nouvelles générations).

Une large part de ce travail porte sur le rôle des médias dans la diffusion du devoir de mémoire. S. Ledoux recense le nombre d'occurrences de l'expression à l'AFP, dans les journaux dont Le Monde et L'Humanité, et explore des sources audiovisuelles (émissions thématiques dont La marche du siècle, bulletins spéciaux, journaux du soir, etc.) pour illustrer l'intérêt croissant du grand public envers cette question. Il postule que les médias sont allés au-delà de leur fonction de caisse de résonnance d'un sujet d'actualité, se sont emparés du devoir de mémoire, et l'ont eux aussi modelé - un point 
intéressant qui prend les médias non comme des relais mais comme des initiateurs de la parole publique. Cependant, le comptage systématique des occurrences à la télévision, la radio et dans la presse d'un mot (mémoire) ou de son association avec d'autres (noms de Barbie, de Jean Moulin) ou de "devoir de mémoire» et Shoah, décèle parfois moins les marqueurs d'une prégnance sociale que ceux d'une visibilité liée à un moment. Une question sous-jacente pourrait ici prolonger ce travail: comment se construit l'interdépendance des discours et des sensibilités sur le devoir de mémoire? Si La marche du siècle sur la mémoire de la Shoah et La liste de Schindler (1992) ont effectivement relancé des débats autour de la Seconde Guerre mondiale, l'inverse est également vrai.

L'auteur discute enfin de l'émergence d'autres mémoires à partir du milieu des années 1990. D'autres génocides (celui des Tutsis), d'autres crimes et conflits (la traite transatlantique, la guerre d'Algérie) apparaissent comme autant de rappels que la mémoire nationale française est également fragmentée en de multiples trajectoires longtemps laissées en marge du récit national. Le devoir de mémoire joue alors à plein son rôle de cadre référentiel. Il permet de solliciter la reconnaissance (et pas encore la réécriture) d'histoires particulières. Il s'agit là de la dernière captation du devoir de mémoire, cette fois lancée par des associations qui poussent les pouvoirs publics à agir et à voter des lois, dont celle reconnaissant le génocide arménien. Dans les années 2000, les usages du devoir de mémoire augmentent encore, trouvent de nouveaux champs d'application comme les programmes scolaires, et lancent de nouvelles lois. Les critiques issues du champ scientifique sont elles aussi de plus en plus nombreuses à l'image de Tzvetan Todorov qui évoque les "abus de la mémoire». Certains hommes politiques brandissent désormais les thèmes de la "repentance" et du "communautarisme" comme des contre-arguments à toute exploration des replis de la narration nationale. Pourtant, la popularité du devoir de mémoire augmente au point qu'il devient une rubrique globale mobilisée au même moment dans différents pays.

Cet ouvrage apporte une réflexion utile sur un sujet qui ne cessera de revenir sur le devant de la scène politique et médiatique. Sa seule limite est que l'auteur ne met pas assez en valeur les nombreuses sources mobilisées (presse régionale et nationale, ouvrages scientifiques et de vulgarisation), particulièrement les entretiens réalisés avec des acteurs de l'époque, comme Robert Badinter ou Jean-Marie Cavada. Cela aurait confirmé, si besoin était, l'importance du travail accompli ici qui, de la généalogie du devoir de mémoire à ses multiples usages, nous permet de comprendre les évolutions d'une société française en peine face aux creux de sa propre mémoire.

Sarah FILA-BAKABADIO Université de Cergy-Pontoise

$\begin{aligned} \text { Muriel Guittat-Naudin, } & \text { Pie XII reste le pape le plus contro- } \\ \text { Pie XII après Pie XII. Histoire d'une controverse, } & \text { versé du XX siècle. Pourtant, au sor- } \\ \text { Paris, Éditions de l'EHESS, 2015, 339p., } & \text { tir de la Seconde Guerre mondiale, à } \\ \text { ISBN 978-2-7132-2489-8 } & \begin{array}{l}\text { la différence de son prédécesseur de } \\ \text { la Grande Guerre, Benoît XV, Pacelli }\end{array}\end{aligned}$
semblait grandi par l'épreuve, même si la question du silence de Rome face au génocide des juifs, venant après le constat de la compromission du Vatican avec les régimes autoritaires ou fascistes dans les années 1930, tourmentait déjà certaines consciences dans les milieux de la Résistance. Mais la légende dorée de Pie XII 
devait bientôt faire place à une légende noire, la pièce de théâtre Le vicaire de Rolf Hochhuth, dont la première fut jouée à Berlin le 22 février 1963, jouant un rôle fondamental dans le retournement de l'opinion publique à l'égard de Pacelli.

Dans cette étude très érudite, qui vise en permanence à la modération et à l'objectivité sur un sujet sensible et polémique, à propos duquel des affirmations partiales et inconciliables se sont toujours opposées frontalement, Muriel GuittatNaudin procède avec méthode pour désarmer la polémique en restituant d'une part la chronologie de la controverse, autour de la rupture décisive du Vicaire, et en démontrant d'autre part que le renversement mémoriel radical se situe à la confluence de trois histoires: la mémoire du génocide des juifs, les enjeux ecclésiaux et les relations judéo-chrétiennes.

Dans les années 1944-1963, une image plutôt positive du pape s'imposa, même si des dissonances s'exprimèrent déjà. Mais l'opinion qui prédominait alors voulait que le Vatican ait respecté les missions traditionnelles de l'Église en temps de guerre, en essayant en particulier de soulager les souffrances des populations civiles et en demeurant, comme il se devait, impartial dans une guerre qui mettait aux prises des catholiques dans les deux camps - impartialité qui n'empêcha cependant pas Pie XII de prendre parti en faveur des démocraties. La légende dorée du pape de la paix, à la charité inlassable, et du "sauveur des juifs", construite par l'institution ecclésiastique elle-même, vola en éclat sous l'effet de l'immense scandale que suscitèrent les premières représentations du Vicaire, mettant en scène un Pie XII indifférent au sort des juifs, à l'exception des baptisés, avant tout soucieux de préserver le concordat avec l'Allemagne nazie et la modération d'Hitler à l'égard de l'Église catholique allemande et, sous l'effet d'un anticommunisme viscéral, soutenant le Führer dans sa guerre contre l'URSS. La polémique fut d'autant plus dévastatrice pour l'image de Pie XII que les ouvrages d'historiens qui parurent alors, comme Pie XII et le III Reich de Saul Friedländer (1964), furent reçus comme une confirmation du Vicaire. L'image d'un pape moralement défaillant devant le génocide se substitua alors à la légende dorée et, depuis la fin des années 1960, sous l'effet d'un renversement mémoriel radical, il est donc admis que Pie XII a assisté sans rien dire à l'extermination des juifs d'Europe, le souverain pontife étant désormais déclaré coupable de s'être tu.

Derrière la chronologie de ce renversement mémoriel, $M$. Guittat-Naudin avance donc trois explications. Les phases d'oubli et de résurgence de la question du silence de Pie XII correspondent aux périodes d'occultation, d'anamnèse et d'hypermnésie du génocide des juifs: occultée dans l'immédiat après-guerre par la mémoire "résistancialiste", la mémoire de l'extermination des juifs d'Europe a ressurgi au début des années 1960 avec le procès Eichmann, à l'origine entre autres de la montée d'une culpabilité chrétienne, avant qu'elle ne tende à devenir le ciment de l'identité juive et le pilier d'une nouvelle religion civique à partir de la fin des années 1970. Mais le silence de Pacelli s'enracinait aussi dans une ecclésiologie selon laquelle l'Église ne devait pas se prononcer sur la nature du régime politique, seules comptant en temps de guerre la défense des droits des catholiques et l'impartialité du Vatican. Or un certain nombre d'intellectuels catholiques ont pu alors estimer que cette attitude traditionnelle était inadaptée aux véritables enjeux du génocide: le pape prudent et diplomate aurait dû céder la place au porteur du message évangélique, à la conscience de l'humanité, garantissant la primauté du spirituel sur les intérêts temporels de l'institution. Le pontificat de Jean-Paul II, apôtre des droits de l'Homme, contribua ainsi à accentuer le discrédit de Pacelli. Enfin, la question des silences de Pie XII 
doit être replacée dans l'histoire des relations judéo-chrétiennes: elle symbolisa progressivement toutes les accusations de l'Église portées à l'encontre du judaïsme. Le scandale du Vicaire, au moment même où s'achevait le concile Vatican II, activa la réflexion sur la culpabilité chrétienne à l'égard de l'antijudaïsme, de l'antisémitisme et du génocide. Si le Vatican évolua de manière significative sur la question du judaïsme dès le pontificat de Jean XXIII, il demeura durablement réservé à l'égard du "geste de réparation" attendu par le monde juif et par une fraction du monde catholique et non-croyant. Si Jean-Paul II, sous la pression des critiques, renonça à béatifier Pacelli, le procès en béatification ne fut pas suspendu pour autant, et la décision prise par son successeur Benoît XVI suscita dans les milieux juifs et laïques une incompréhension totale.

Pacelli fut avant tout un intellectuel diplomate et traditionnaliste, germanophile et foncièrement anticommuniste, qui ne s'engagea clairement aux côtés des démocraties occidentales que dans le contexte de la Guerre froide. Il est devenu depuis les années 1970 un "pape qui ne passe pas». Par-delà la délicate question controversée de ses silences, l'opprobre qui l'accable tient aussi à la remise en cause de l'institution tout entière sur la question de l'antijudaïsme et à l'émergence récente, au sein du monde catholique, du modèle exemplaire d'une papauté spirituelle, évangélique et prophétique, en rupture totale avec la prudence d'un Pacelli. La lecture de l'ouvrage de M. Guittat-Naudin nous suggère donc que la légende noire de Pie XII comporte, comme la légende dorée, une part d'injustice, en partie liée à l'anachronisme.

Michel FABRÉGUET

Université de Strasbourg

\author{
Françols Azouvi, \\ Le mythe du grand silence. Auschwitz, \\ les Français, la mémoire, \\ Paris, Folio-Gallimard, 2015, 695 p., \\ ISBN 978-2-07-046512-5
}

Ce livre est une réédition augmentée de celui paru initialement chez Fayard en 2012. Ce travail très richement documenté, effectué par un non-historien (l'auteur est philosophe de formation) constitue une contribution précieuse à

l'histoire de la mémoire de la Shoah en France, en marquant une nouvelle approche de la question. Le cœur de sa démonstration - explicitement énoncée dans le titre du livre - est la réfutation de ce qu'il nomme dès les premières lignes «la thèse du grand silence autour du génocide des juifs» (p. 15). Il est important de relever que le propos s'inscrit à l'échelle internationale dans une nouvelle historiographie qui réévalue la présence du génocide au sein des sociétés occidentales de 1945 aux années 1960, une période qualifiée d'oubli ou de silence par un certain nombre d'historiens depuis la fin des années 1980. Les travaux d'Hasia Diner avaient déjà auparavant abouti aux mêmes conclusions pour les États-Unis, en mettant en exergue de multiples évocations de la Shoah au sein de la communauté juive nordaméricaine lors de cette période (We Remember with Reverence and Love: American Fews and the Myth of Silence after the Holocaust, 1945-1962, 2009).

Déconstruisant le schéma narratif dominant «refoulement/ retour du refoulé/ obsession", François Azouvi développe son argumentation en trois parties chronologiques: «Le génocide dans la culture française» de septembre 1944 à novembre 1961, "Le génocide dans l'espace public» de 1961 à 1967 avec la guerre des Six Jours, et enfin "Le génocide dans la sphère de l'État» de la grâce de Touvier (1971) au procès 
Barbie (1987). Ces temporalités suggèrent une imprégnation progressive de la mémoire de la Shoah en France, touchant des cercles toujours plus larges: au départ les élites culturelles, puis l'espace public et enfin l'action publique.

L'auteur consacre une très large part de son livre aux milieux intellectuels catholiques et protestants, ainsi qu'aux productions littéraires et cinématographiques qui évoquent le génocide, de la fin de la guerre au début des années 1960. Le grand intérêt de ce travail réside dans la présentation de très nombreux textes, ouvrages et films démontrant de manière indiscutable les diverses formes d'expressions que ce passé a pu alors susciter de façon continue. L'entrée de la mémoire du génocide dans l'opinion publique française au cours des années 1960 est repérée par F. Azouvi à la faveur des débats autour de la pièce Le vicaire (1963-1966). Cette référence, à laquelle il faut ajouter la controverse provoquée par la parution en 1966 du livre Treblinka de Jean-François Steiner, bien analysé par Samuel Moyn (A Holocaust Controversy: The Treblinka Affair in Postwar France, 2005), a le mérite de nous rappeler la pertinence de l'échelle nationale dans l'étude de la mise en mémoire du génocide, jusque-là occultée par un récit globalisant faisant du procès Eichmann (1961) et de la guerre des Six Jours des dates charnières exclusives.

La troisième partie, qui traite des années 1970-1980, appelle quelques réserves. Les faits rapportés sont nombreux et significatifs, mais l'impression d'un catalogue de dates sans réelle mise en perspective, mêlant indistinctement faits culturels, politiques ou sociaux, finit par l'emporter. Il en ressort une périodisation qui manque de relief et qui reste cette fois-ci traditionnelle, en attachant trop d'importance aux années 1970, sans relever les mutations sociales des années 1980, qui ont des effets déterminants sur le passé étudié. Entre autres, la question du traumatisme et le statut de victime deviennent des catégories sociales particulièrement opérantes dans cette décennie, ce qui offre un cadre d'intelligibilité et donc d'appropriation inédit pour le génocide des juifs. Par ailleurs, l'événement fait l'objet d'une mise à l'agenda progressive du politique - c'est très net avec la commémoration du Vel d'Hiv' - au cours des années 1980. La question du génocide est construite comme problème public par différents acteurs (politiques, médias, entrepreneurs de mémoire, scientifiques) au tournant des années 1980-1990, dans une nouvelle configuration qui mêle la lutte contre l'antisémitisme et le négationnisme, la montée du Front national et la qualification d'une «France-malade-de-son passé» vichyssois antisémite, un problème appelant une intervention des pouvoirs publics au plus haut niveau. Les années 1990, présentées seulement dans l'épilogue de l'ouvrage, voient pourtant la mémoire de la Shoah devenir un cadre référentiel, avec l'instauration d'une politique publique à son sujet qui engage l'État français dans des actions de réparation symbolique et matérielle.

Malgré ces limites, le travail de F. Azouvi marque une étape importante dans le champ historiographique des études sur la mémoire de la Shoah. L'ouvrage a en effet ouvert un nouveau chantier en France - que des historiens prolongent aujourd'hui en s'attaquant frontalement à la doxa en vigueur depuis alors plus d'une vingtaine d'années, ce qui relève aussi d'un certain courage, tant l'objet est symboliquement fortement investi. La question que soulève l'auteur dans sa postface apparaît d'ailleurs particulièrement féconde: «Pourquoi avons-nous oublié que nous n'avions pas oublié ?" (p. 564). Elle ouvre des réflexions plus générales sur le rôle social de l'historien et le rapport des contemporains au passé, dans le cadre d'une nouvelle économie morale. Les demandes de reconnaissance et de réparations pour les victimes de certains faits du passé catégorisés comme traumatiques ont en effet souvent été 
légitimées par des mises en récit publiques statuant sur leur oubli, leur refoulement ou leur occultation. Cette grille interprétative a concerné en France non seulement la Shoah, mais aussi la guerre d'Algérie ainsi que la traite et l'esclavage, à partir des années 1990. Ce livre touche par conséquent un point extrêmement sensible de la démarche ontologique de l'historien, tournée vers le recouvrement des traces du passé, en démontrant que ce récit du silence de la mémoire de la Shoah s'est élaboré avec la caution scientifique de certains historiens. Il n'en est que plus utile.

Sébastien LEDOUX Centre d'histoire sociale du xxe siècle (UMR 8058), Université Paris 1

$\begin{aligned} & \text { JACOB S. EDER, } \text { Les études relatives à la prise en charge } \\ & \text { Holocaust Angst. The Federal Republic } \text { par l'Allemagne de son passé nazi (Ver- } \\ & \text { gangenheitsbewältigung) sont déjà très } \\ & \text { since the 1970s, } \\ & \text { nombreuses, avec un effort récent pour } \\ & \text { of Germany and American Holocaust Memory } \\ & \text { Oxford, Oxford University Press, 2016, 296 p.r } \\ & \text { ISBN 978-0-19-023782-0 } \\ & \begin{array}{l}\text { comparatif et transnational (Frank } \\ \text { Biess, Robert Moeller (éd.), Histories of }\end{array}\end{aligned}$
the Aftermath. The legacies of the Second World War in Europe, 2010; José Brunner, Constantin Goschler, Norbert Frei (éd.), Die Globalisierung der Wiedergutmachung. Politik, Moral, Moralpolitik, 2013). Le livre tiré de sa thèse par Jacob Eder s'inscrit dans cette voie permettant d'enrichir l'histoire très contemporaine de l'Allemagne. Si la position des organisations juives étasuniennes vis-à-vis de la RFA pendant la Guerre froide a déjà fait l'objet d'analyses, l'auteur choisit d'inverser la perspective en portant son attention sur l'attitude des responsables ouest-allemands à l'égard de ces organisations et plus largement de la mémoire étasunienne de l'Holocauste. Sa recherche innovante s'appuie sur des archives nord-américaines (United States Holocaust Memorial Museum, association American Jewish Committee) et ouestallemandes (Archives des Affaires étrangères à Bonn, Archives fédérales de Coblence, ambassade de RFA à Washington) dont certaines inédites, ainsi que sur une trentaine d'entretiens.

Alors que la RFA entretient avec les États-Unis une relation privilégiée depuis le début de la Guerre froide en matière économique, diplomatique et militaire, l'«américanisation» de la mémoire de l'Holocauste vient perturber la relation germano-américaine. Cette mémoire constitue progressivement, entre la fin des années 1970 et le milieu des années 1990, une référence historique et morale majeure dans la société étasunienne par le biais notamment de productions audiovisuelles (téléfilm Holocaust en 1978-1979), du projet de création du United States Holocaust Memorial Museum (USHMM) entre 1979 et 1993, ou de controverses (Bitburg en 1985). Le livre présente et analyse la façon dont les dirigeants, diplomates et ONG de l'Allemagne de l'Ouest ont perçu cette évolution et ont réagi face à ce nouveau cadre de référence mémoriel. L'auteur distingue deux périodes.

Dans un premier temps (1982-1990), certains membres influents du Parti chrétien-démocrate allemand (CDU), constitués en partie d'anciens officiers nazis de la Seconde Guerre mondiale, ainsi que le chancelier Helmut Kohl et ses conseillers, se sont perçus comme des victimes de la mémorialisation de l'Holocauste mise en œuvre aux États-Unis, notamment par les organisations juives. J. Eder relève dans cette attitude la trace, à l'encontre des juifs américains, de forts préjugés et de 
stéréotypes partagés par cette classe politique ouest-allemande persuadée du pouvoir d'influence considérable du lobby juif sur la politique étasunienne et de son désir de ne pas pardonner aux Allemands leur entreprise génocidaire pendant la Seconde Guerre mondiale. Ce personnel politique ouest-allemand a au départ considéré le nouvel intérêt des Américains envers l'Holocauste comme une menace pour l'image de la RFA sur la scène internationale, et une pierre d'achoppement dans les relations si cruciales avec leur partenaire nord-américain. La nouvelle place occupée par l'Holocauste dans la société étasunienne a ainsi provoqué un sentiment d'angoisse (Holocaust Angst) chez les diplomates en poste et parmi les conservateurs de la CDU au pouvoir en RFA à partir de 1982. L'auteur montre qu'une telle évolution contrariait les efforts entrepris alors par les conservateurs et certains intellectuels allemands pour "dé-stigmatiser le passé national", en présentant le III Reich et l'Holocauste comme une aberration de l'histoire allemande dont il fallait mettre en avant les aspects positifs. J. Eder développe longuement les enjeux autour du projet d'un musée de la mémoire de l'Holocauste à Washington, perçu au cours des années 1980 par Kohl et ses conseillers comme un «musée anti-allemand». Il présente avec précision les nombreuses tentatives ouest-allemandes pour intégrer dans ce musée l'histoire de la résistance allemande au nazisme et l'histoire allemande de l'aprèsguerre. Parallèlement, une coopération étroite est entreprise par le gouvernement de la RFA avec des historiens et intellectuels allemands pour promouvoir, par des institutions situées aux États-Unis (Goethe Institut ou DAAD, l'office allemand des échanges académiques), un récit national valorisant l'image de l'Allemagne. Le livre rend compte des actions et discours des représentants de la RFA, en détaillant le rôle joué par certains acteurs (intellectuels, historiens, hommes d'affaires, ONG, institutions culturelles) dans cette entreprise narrative de réhabilitation.

La deuxième période étudiée (1990-1998) marque, selon J. Eder, un changement radical à l'égard de la mémoire de l'Holocauste, qui est entrepris par les dirigeants d'une Allemagne désormais réunifiée, et qui concerne tant sa politique mémorielle nationale que sa relation avec les États-Unis. Pour expliquer ce tournant engageant l'État allemand dans une mémorialisation de l'Holocauste, qui en fait l'une des composantes majeures de son récit national, l'historien allemand évoque les controverses publiques très vives qui interviennent en Allemagne au milieu des années 1990 autour de La liste de Schindler de Spielberg ou du livre de Daniel Goldhagen (Hitler's Willing Executioners, 1996) et sont particulièrement suivies par la chancellerie et les diplomates en poste aux États-Unis. L'arrivée au pouvoir d'une génération qui n'a pas été impliquée dans le crime génocidaire favorise aussi cette reconfiguration. L'auteur met également en avant le nouveau regard porté sur la mémoire de l'Holocauste par le chancelier Kohl, qui y voit désormais une ressource positive potentielle à la fois sur le plan intérieur, et au bénéfice de l'image internationale de l'Allemagne et de sa politique étrangère.

Par son approche comparative et transnationale, le travail de J. Eder apporte une contribution à la compréhension de la globalisation de la mémoire et s'inscrit dans les pistes de recherche ouvertes depuis une dizaine d'années par les Memory studies (Aleida Assmann, Sebastian Conrad (éd.), Memory in a Global Age, 2010; Daniel Levy, Natan Sznaider, The Holocaust and Memory in the Global Age, 2006). Un tel ouvrage montre une nouvelle fois les enjeux que porte aujourd'hui la mémoire - ce "présent du passé» selon la définition de Saint Augustin - et son rôle non négligeable dans les relations interétatiques. L'attention portée aux dynamiques transnationales 
des mémoires ne traduit pas, comme le démontre ce travail de J. Eder, l'effacement ou la minoration des ressources et cadres proprement nationaux. Elle souligne la prise en compte nécessaire des jeux d'échelle et des multiples interactions qui opèrent dans la mise en mémoire du passé par les sociétés contemporaines.

Sébastien Ledoux

Centre d'histoire sociale du xxe siècle (UMR 8058), Université Paris 1

Benoît Falaize,

L'histoire à l'école élémentaire depuis 1945,

Rennes, Presses universitaires de Rennes, 2016,

331 p., ISBN 978-2-7535-4357-7
Issu d'une thèse, cet ouvrage est consacré à l'histoire de l'enseignement de l'histoire à l'école élémentaire de la Libération à nos jours. Comme le souligne Benoît Falaize dans une intro-

duction qui doit retenir l'attention du lecteur, c'était un "chantier déserté" par les historiens, avec une seule thèse spécifiquement consacrée à l'enseignement de l'histoire à l'école primaire, celle de B. Dancel sur la III République. D'emblée, il pose une question qui traverse l'ouvrage: comment, au sortir de la Seconde Guerre mondiale et de ses traumatismes et jusqu'au début du XXI ${ }^{\mathrm{e}}$ siècle, les instituteurs et les institutrices ont-ils continué à enseigner l'histoire? L'auteur privilégie deux angles d'attaque: l'analyse des débats pédagogiques témoignant des pratiques en cours et influençant en retour les démarches scolaires, l'examen des pratiques scolaires avec l'ambition d'ouvrir la boîte noire du quotidien des élèves. Pour mener à bien son projet, il a rassemblé un corpus varié de sources comprenant les revues pédagogiques (en particulier le fournal des instituteurs et le Manuel général), les dossiers individuels de carrière des enseignants de la Charente-Maritime contenant leurs rapports d'inspection, enfin des cahiers de classe conservés au Musée national de l'éducation de Rouen. Le plan s'articule en cinq tranches chronologiques, 1945-1958, 1958-1969, 1969-1978, 1978-1985, 1985-2002, complétées par un chapitre sur l'histoire à l'école élémentaire dans les colonies et par un ultime chapitre faisant le point sur la situation de l'enseignement de l'histoire à l'aube du $\mathrm{XXI}^{\mathrm{e}}$ siècle.

«Faut-il enseigner l'histoire à l'école primaire?» Cette interrogation d'un professeur de psychopédagogie témoigne des doutes persistants traversant la communauté éducative dans les années 1945-1958. Que proposent les instructions de décembre 1945 et de juillet 1947 complétées en 1957 par plusieurs circulaires? Un enseignement de l'histoire en continuité avec celui de la III ${ }^{\mathrm{e}}$ République, mettant l'accent sur le recours à l'histoire locale. Si la leçon d'histoire reste une leçon de morale, de civisme et de patriotisme, on peut cependant relever dans ces textes une nouveauté qui rencontre un assentiment massif: la place prise par l'histoire de la vie quotidienne, venant équilibrer le poids de l'histoire-bataille. L'analyse des pratiques effectives montre que c'est au cours moyen et dans les classes de fin d'études que le programme fixé par les instructions est le plus suivi et que s'organisent la majorité des apprentissages. Elle met aussi en lumière une relative pauvreté des contenus enseignés, et une absence totale de réflexion sur ce que la société d'après-guerre attend de l'enseignement de l'histoire. Enfermée dans des pratiques routinières, l'École ne parvient pas alors à proposer une redéfinition de l'histoire enseignée en accord avec son époque.

Placées sous le signe de débats récurrents autour de la didactique de l'histoire, les années 1958-1969 sont aussi le temps des premières grandes enquêtes (J. Hanriot 
en 1955-1957, M. Debesse en 1968) posant la question du rapport de l'enfant à l'histoire. Inspirées par les travaux de Piaget, leurs conclusions sont nuancées. Si le sens du temps et la compréhension de l'histoire sont plus développés qu'on ne le dit chez l'enfant de 10-11 ans, les liens de causalité en histoire économique et politique lui échappent. "Son domaine de prédilection reste l'événementiel». C'est aussi pendant ces années que paraît l'ouvrage de J. Natanson et A. Prost, La révolution scolaire (1963). Observateurs de l'impasse dans laquelle est engagé l'enseignement traditionnel de l'histoire, ces deux auteurs ouvrent de nouvelles perspectives pour cette discipline à l'école élémentaire: rupture avec l'histoire-récit et sa dimension édifiante, enseignement d'une histoire des civilisations orientée vers la compréhension de l'homme "dans sa dépendance à l'égard des civilisations". Pour répondre aux attentes des maîtres sur la manière d'enseigner l'histoire, les revues proposent un véritable aggiornamento pédagogique en recommandant l'utilisation systématique du document qui ne serait plus, comme le disent les instructions, un outil parmi d'autres mais le socle de la leçon. De leur côté, les rapports des inspecteurs et les cahiers de classe confirment les résultats des enquêtes: l'histoire enseignée reste bien traditionnelle dans ses contenus et ses démarches, même si les nouveaux outils que sont les diapositives, les films et les documents devraient inciter à leur renouvellement.

Pour son enquête sur l'histoire enseignée dans les colonies de 1902 à 1962, l'auteur retient deux exemples: l'Afrique occidentale française et le Maghreb. Revenant sur l'idée communément admise d'un enseignement de l'histoire conçu comme le décalque de celui dispensé en métropole, l'auteur montre que, bien au contraire, l'histoire et les cultures locales abordées par le biais de méthodes actives sont largement prises en compte. Dans ce contexte, l'enseignement de l'histoire entend intégrer la "petite patrie» à la grande France. Cette démarche annonce celle qui prendra naissance en métropole à la fin des années 1960 avec la pédagogie de l'éveil. On notera la réserve apportée par l'auteur quand il évoque la marginalité du taux de scolarisation, de nature à limiter l'influence réelle de l'enseignement de l'histoire dans les colonies.

Les chapitres V et VI sont consacrés à ce qui restera dans l'histoire de l'école primaire des années 1969-1985 comme le temps des activités d'éveil instituées en 1969, dans le cadre du tiers-temps pédagogique. Concernant leur mise en œuvre entre 1969 et 1978, l'auteur insiste sur ce qui les a pénalisées: l'absence de programme en a fait un navire sans boussole. L'analyse des revues lui permet de pointer les difficultés auxquelles ont été confrontées l'histoire et la géographie dans ce contexte. Les rapports des inspecteurs et les cahiers d'élèves mettent en évidence un réel appauvrissement de l'enseignement de l'histoire. Cette situation est à l'origine du grand débat de la fin des années 1970, dans lequel des personnalités politiques et universitaires interviennent pour annoncer la mort de l'histoire. Afin de répondre aux inquiétudes des parents et des spécialistes, des instructions sont publiées en 1978. L'auteur montre qu'elles ne mettent pas fin au désarroi des maîtres, dont les démarches restent globalement disparates, sans cohérence réelle. Il note également l'apparition pendant ces années d'un nouveau paradigme pour la culture scolaire: celui de la question nationale. Il est à l'origine de la redéfinition en 1985 de la place de l'enseignement de l'histoire nationale dans la formation des élèves de l'école élémentaire.

Dans le nouveau contexte historiographique actant le retour de l'histoire-récit, mais d'un récit apaisé, de nouveaux programmes sont publiés en 1985, 1995 et 2002, se ressemblant fortement dans leurs contenus et dans leurs prescriptions. Les élèves doivent acquérir des savoirs construits chronologiquement, des repères organisés 
autour d'une histoire nationale élargie. Manifestement, ces textes veulent, comme en 1978, répondre aux inquiétudes des parents et aux groupes politiques pour lesquels l'histoire doit prendre en compte la mémoire de dates, d'événements et de grands personnages. Quant aux pratiques, les nouvelles enquêtes de didactique qui, cette fois, cherchent à saisir les situations réelles de classe, les rapports des inspecteurs et les travaux des élèves montrent leur évolution dans le sens d'une secondarisation, tant dans les formes que dans le contenu.

Qu'en est-il de l'enseignement de l'histoire à l'école élémentaire à l'aube du $\mathrm{XXI}^{\mathrm{e}}$ siècle, alors que les programmes ont encore été modifiés en 2008 ? Il est difficile de répondre à cette question en raison de la rareté et du caractère parcellaire des recherches en didactique de l'histoire à ce niveau. L'absence de grande enquête nationale interdit toute généralisation. L'auteur n'en formule pas moins plusieurs constats. C'est tout d'abord le consensus très large sur la difficulté à fonder un enseignement de l'histoire pour les plus jeunes des élèves. Ce sentiment se nourrit chez les enseignants des difficultés qu'ils rencontrent pour maîtriser un champ de connaissances particulièrement riche. Ce qui pose à l'évidence le problème de leur formation. C'est ensuite la mise en évidence, par les cahiers, que l'école parvient à fournir aux élèves des repères sur les personnages et sur les évènements majeurs du passé collectif. L'école continuerait donc de donner un cadre légitime d'interprétation du passé. Bien des questions restent cependant posées.

Il faut souligner la richesse d'un livre qui vient remplir avec bonheur un vide historiographique. La rigueur de ses analyses, fondées sur une ample documentation, en fait une référence indispensable pour tous ceux qui s'interrogent sur le type d'histoire qu'il convient d'enseigner à l'école élémentaire et les méthodes à employer. Ce retour sur les mutations de cet enseignement de la Libération à nos jours est indispensable pour comprendre les débats récurrents qu'il suscite toujours. Mais au-delà de l'histoire d'une discipline scolaire, c'est celle du rôle de l'école dans la société que nous invite à découvrir B. Falaize. Il faut souhaiter que les futurs enseignants de l'école élémentaire en formation dans les ESPE s'emparent de son livre et le méditent. Il faut aussi en recommander vivement la lecture à tous ceux qui s'intéressent à l'histoire de la culture scolaire.

Philippe MARCHAND IRHiS (UMR 8529), Université de Lille

\author{
Francesco Benigno, \\ Las palabras del tiempo. \\ Un ideario para pensar históricamente, \\ Madrid, Cátedra, 2013, 304 p., \\ ISBN 978-84-376-3142-4
}

Rassemblant des articles publiés dans des revues, des contributions à des séminaires et des chapitres remaniés de livres écrits dans les années 2005-2012, cet ouvrage offre aux lecteurs une analyse critique de notions-clés de l'historiographie européenne. Il vise à combler les lacunes de la réflexion historienne sur l'usage de certains concepts pourtant largement employés dans cette discipline.

Le recueil illustre la volonté de l'auteur d'entretenir une réflexion permanente sur les mots et les expressions employés en histoire, ce qui recouvre le domaine de «l'histoire conceptuelle». Si les neuf notions présentées de manière critique n'offrent pas toutes une réflexion également poussée ou complètement novatrice, plusieurs font l'objet de remarquables analyses, tant du point de vue de l'histoire de la notion 
que de ses critiques épistémologiques. Pour exposer ces travaux, élaborés à des moments différents, Francesco Benigno présente dans son introduction, avec une grande rigueur et une certaine puissance intellectuelle, les réflexions qui permettent de contextualiser l'histoire conceptuelle (p. 31-54): il relie ainsi ces neuf chapitres, mais surtout il définit mieux l'objet même de l'histoire des concepts, ainsi que ses méthodes. Considérant que les concepts précèdent l'observation, que la perception est largement une élaboration de ce qui est déjà connu (une re-connaissance), que les grandes catégories intellectuelles formatent et conditionnent les analyses, F. Benigno insiste sur les dangers de l'empirisme et sur ceux de la rétroprojection qui interprète le passé en fonction des catégories actuelles, sans en avoir conscience. En cela, l'introduction donne quitus au révisionnisme historique et à l'attitude antitéléologique pour approcher les sources du passé (rappelant au passage le titre du livre de David Lowenthal, The Past is a Foreign Country, 1985).

À la suite du Linguistic Turn, et dans le cadre de cette Begriffsgeschichte (histoire des concepts), les références de F. Benigno aux travaux de Reinhard Koselleck et à d'autres penseurs allemands sont nombreuses, afin d'insister sur le moment de rupture (Sattelzeit) qui se produit autour des années 1990. Or, pour F. Benigno, cette rupture ne peut plus être réduite à la seule révolution conservatrice. En effet, la postmodernité provient plus largement de la conscience de la finitude d'un monde qui rompt avec la modernité politique où l'on a puisé dans la Révolution française; cette postmodernité rompt aussi avec la croyance dans la puissance des États, à un moment où le marché global ne cesse de réduire leur marge de manœuvre et de leur imposer la fin du Welfare State dans les principaux pays occidentaux. Enfin, elle rompt avec l'idée même du progrès continu des sociétés, depuis que l'on sait que la finitude du monde peut aller jusqu'à la destruction de la Terre et que de nouveaux défis - sanitaires et médicaux en particulier - menacent tout progrès. Ces divers éléments participent à ce nouveau "régime d'historicité». Ils nécessitent de repenser les outils conceptuels traditionnels de l'histoire alors que les attentes sociales envers cette discipline ne cessent de se transformer. En effet, le poids croissant assigné à la mémoire se fond de plus en plus fréquemment dans une histoire "émotive", sinon des émotions, que la puissance médiatique transmet et diffuse à de larges publics par le biais de médias variés. Ces dernières années, les historiens sont concurrencés par de nouveaux acteurs et producteurs du passé, la divulgation transite selon des mécanismes de mémorialisation nouveaux. La quête mémorielle à laquelle aspirent les sociétés contemporaines ne porte plus directement sur le passé et recherche l'exposition du trauma social par le biais de processus de spectacularisation et de fictionnalisation des antécédents, dans une sorte d'anamnèse collective qui permettrait de nommer les maux dont chacun a souffert afin de mieux identifier victimes et bourreaux. Ces deux derniers termes modifient la clé d'interprétation précédente, qui traitait plutôt des rapports entre opprimés et oppresseurs.

Ainsi que le note F. Benigno, ces mécanismes de consommation de l'histoire actualisent en permanence certains souvenirs et les ajustent à la demande sociale. Dès lors, le travail de l'historien, selon l'auteur, devrait tendre à offrir un instrument de travail pour penser l'outillage intellectuel, ce qui fait l'objet de l'exposé de neuf notions communément utilisées. Cette réévaluation repose donc sur le constat de la transformation du monde et sur la nécessaire mutation des catégories conceptuelles, rendues parfois inopérantes. Ces neuf études sont fort intéressantes, mais plus que leur contenu épistémologique, la démarche présentée dans les vingt premières pages s'avère convaincante, venant d'un auteur qui ne cache pas ses idées et son engagement 
dans la discipline. L'application de cette réévaluation à la notion d'identité (p. 55-82) repose sur une discussion des travaux de Zygmunt Bauman (L'amour liquide, 2004, et La vie liquide, 2006) et de la question de la décomposition et de la recomposition des associations collectives, c'est-à-dire des fondements des identités sociales, qu'elles soient de classe ou nationales. Réfutant la vision nationale, F. Benigno présente les nouvelles façons de les penser pratiquées depuis un quart de siècle environ (et la dilution de la modernité), par exemple en termes de cour, de réseaux, de factions, de clientèles, voire à partir de la microstoria - de l'individu et du local - ou encore par la possibilité de penser la distance avec la société passée, en utilisant les termes qu'elle-même employait, tels que les notions d'ordres, de rites, etc. Ceci confirme que les catégories identitaires classent et catégorisent, mais que l'identité elle-même apparait comme une catégorie mouvante, "amphibie» et que son emploi pose autant de problèmes que de solutions.

L'ambivalence d'un concept de "génération" (p. 83-106), récusé comme inopérant par Lucien Febvre, et pourtant utilisé en démographie, relève des deux sens que lui avait donnés Karl Mannheim - le sens positiviste (français) et le sens romantique (allemand) - qui refléteraient deux démarches: l'une fondée sur l'idée de progrès, l'autre plus pessimiste, fondée sur l'expérience de vie. Toutefois, la "génération" n'est jamais univoque et se forge a posteriori, par un processus de reconstruction mémorielle (Pierre Nora) des événements afin de donner sens à un passé qui, bien souvent, ne concerne pas tous les membres de la génération, loin de là.

La réflexion sur le thème de la culture populaire (p. 107-146) apparaît plus classique, car son histoire et les critiques formulées sont bien connues, l'actualité de la postmodernité scellant la fin de la bipolarité peuple-élite et le déclin de cette thématique, selon l'auteur. En revanche, son analyse de la violence (p. 147-174) paraît d'une actualité brûlante. D'abord fille de la politique, puis attribuée aux conséquences du trauma par les anthropologues, qui la reconnaissent dans les rapports sociaux par les rites et les gestes, la violence est considérée comme transgression illégitime de l'emploi de la force qui, elle, serait légitime. La légitimité réapparait avec le concept de pouvoir (p. 175-198), sachant que les termes allemands de Macht (le pouvoir avec la capacité de réaliser une action publique contre la volonté des autres) et Herrschaft (le pouvoir légitime) la recouvrent. Dans les années 1950, le pouvoir est dégagé de l'unique emprise de l'État avec Pierre Clastres (La société contre l'État, 1974) qui observe les sociétés sans État, ce que prolongèrent les réflexions de Foucault sur le mécanisme du pouvoir bien plus que sur son appropriation. La notion d'État moderne, considérée comme inopérante (p. 200), fait l'objet d'une belle démonstration qui se trouve démentie quand F. Benigno l'emploie «naturellement» (p. 272): l'usage du quotidien refait surface, malgré l'intelligence du critique.

Les trois derniers concepts présentés - révolutions, opinion publique et Méditerranée - offrent cette même gamme de réflexion épistémologique. Chaque fois, l'auteur puise ses analyses auprès d'un très grand nombre d'historiens, de philosophes et de sociologues d'horizons extrêmement variés, allemands, français, italiens, espagnols, anglais, américains, etc. À l'âge historique de la postmodernité, F. Benigno contribue fortement à désenclaver les histoires nationales des concepts qui les ont formées. À ce moment-clé de la mondialisation et de la connexion du monde, il reste à rechercher les références des penseurs contemporains extra-européens qui correspondent à des régimes d'historicité distincts. 


\section{NinA KUSHNER, Erotic Exchanges. The World of Elite Prostitution in Eighteenth-Century Paris, Ithaca, Cornell University Press, 2013, XIV + 295 p., ISBN 978-0-8014-5156-0}

La prostitution et la police des mours au XVIII ${ }^{e}$ siècle d'Érica-Marie Benabou, publié à titre posthume en 1987, demeure à ce jour un travail de référence concernant la prostitution et la déviance sexuelle dans le Paris de l'Ancien Régime. Il est

à ce titre encourageant de constater que de nombreux ouvrages récemment publiés s'appuient sur cette œuvre. On peut citer par exemple Un policier des Lumières de Vincent Milliot (2011), qui s'intéresse au système policier, ou les travaux réunis par Markman Ellis et Ann Lewis sous le titre Prostitution and Eighteenth-century Culture: Sex, Commerce and Morality (2012), qui explorent les cultures littéraires et visuelles françaises et étrangères.

Le travail de Nina Kushner s'intègre de manière remarquable à cet ensemble. Il s'appuie pour l'essentiel sur les mêmes sources qu'É.-M. Benabou, en particulier les archives de la police parisienne, restreintes aux années 1747-1771, et particulièrement riches. Cependant, utilisant une approche originale, l'auteure nous offre plus qu'un simple approfondissement de ce champ. En premier lieu, elle s'intéresse plus particulièrement à la prostitution d'élite. En excluant de ses recherches les prostituées de rue, de loin les plus nombreuses, elle arrive à définir la sous-culture de la prostitution élitaire. Selon N. Kushner, l'échelle englobante utilisée par É.-M. Benabou a conduit à mélanger cette sous-culture avec les autres formes de prostitution, évacuant ainsi ses spécificités. Les maîtresses de l'élite sociale de Paris constituent l'objet d'étude principal de cette étude, la plupart d'entre elles ayant commencé leur carrière en tant qu'actrices ou danseuses. En second lieu, l'auteure souhaite éviter l'approche régulationniste qui, selon elle, caractérise le travail d'É.-M. Benabou, en interprétant les archives policières de telle sorte qu'elles puissent éclairer les expériences personnelles de ces femmes, "de bas en haut».

La troisième particularité de ce travail consiste à envisager la prostitution comme un simple travail d'ordre sexuel. Cette conception et les perspectives qu'elle ouvre, si répandues de nos jours, ne l'étaient pas à l'époque du livre d'É.-M. Benabou. L'approche est d'autant plus intéressante que les archives elles-mêmes soutiennent aisément cette démarche, recelant en effet de nombreuses informations légales ou économiques concernant le commerce du sexe. N. Kushner éclaire de manière fascinante tous les aspects de la vie professionnelle de son sujet d'étude, de la sociologie et de la géographie des échanges aux relations avec les clients, du rôle des tenanciers de maisons closes à la place surprenante occupée par les petits amis (les "greluchons") des prostituées dans leur vie. Des normes sociales régulaient ces pratiques, et étaient respectées par la police elle-même. N. Kushner affirme ainsi que la surveillance exercée par cette dernière était plus bienveillante que celle appliquée aux autres activités féminines d'ordre non sexuel. Ses aspects moralisants étaient très légers, et la police n'intervenait que lorsque l'honneur d'une famille était en jeu, ou quand un scandale public menaçait d'éclater.

Devenir une femme entretenue impliquait la plupart du temps de signer un contrat généralement très favorable aux femmes concernées. Elles avaient par exemple souvent le droit de conserver tous les cadeaux qui leur avaient été offerts. Un "pot-de-vin" accompagnait invariablement la signature du contrat, tandis que chaque nouvelle année leur apportait des "étrennes». Les rémunérations pouvaient dans certains cas se révéler fabuleuses. Mais bien que le revenu médian soit plus modeste (N. Kushner l'estime à environ 600 livres annuelles), il restait bien supérieur à celui des autres activités féminines. Les femmes employées dans le secteur textile gagnaient entre 36 et 
100 livres par an, une "marchande de mode» entre 150 et 200 . Les femmes entretenues de N. Kushner appartenaient donc à la petite élite de femmes célibataires capables de prospérer financièrement hors des liens du mariage, en tant qu'agents indépendants, alors que la vie des autres femmes tournait autour d'une "économie de l'honneur" dérivée du mariage. S’appuyant sur les analyses de Pierre Bourdieu, N. Kushner considère que ces femmes d'élite cultivaient ce qu'elle appelle leur "capital sexuel", "un actif personnel, similaire au capital social, économique ou culturel» (p. 154).

Si l'approche de N. Kushner s'inspire des analyses sociologiques contemporaines des travailleuses du sexe, le portrait qu'elle dresse de ce commerce au XVIII ${ }^{\mathrm{e}}$ siècle semble bien rose par rapport à ce que nous savons de lui aujourd'hui, parce qu'elle s'est limitée à l'élite des femmes entretenues, et non à la masse des prostituées de rue. Plus important encore, en s'intéressant uniquement à une période de 25 ans, elle s'interdit toute analyse longitudinale. Combien de ces femmes bien payées ont utilisé leur période de désirabilité pour se constituer un patrimoine solide ? Combien d'entre elles ont fini dans la misère? Leurs habitudes de consommation somptuaires suggèrent un chiffre élevé. Par ailleurs, étant donnée la préférence des clients envers la chair fraîche et pré-nubile, tout indique qu'à l'âge de trente ans la carrière d'élite de ces femmes était invariablement terminée. Pour beaucoup, le trottoir les attendait. En réalité, le "capital sexuel» ne durait pas longtemps, et il n'explique que bien peu de chose. Ceci est d'autant plus vrai que la période étudiée par N. Kushner, les années 1747-1771, correspond à une explosion de la culture de la consommation à Paris. Le "capital sexuel» pourrait se révéler bien plus fragile hors des années inhabituellement tolérantes et prospères étudiées ici. La situation décrite serait-elle la même dans un contexte économique plus difficile? Ou sous le règne d'un monarque moins tolérant que Louis XV en matière de comportement sexuel? Ou sous la République? Certaines réponses à ces questions peuvent être trouvées dans la thèse de Clyde Plumauzille récemment publiée (Prostitution et Révolution. Les femmes publiques dans la cité républicaine (1789-1804), 2016). Il serait également intéressant d'en apprendre davantage sur la manière dont la vie de courtisane interférait avec les carrières féminines à l'opéra ou au théâtre, ou de posséder une idée plus précise des normes sexuelles et sociales dans lesquelles évoluaient leurs compagnons. Les recherches de N. Kushner nous incitent à vouloir en savoir plus sur le monde fascinant qu'elle explore - ce qui est une manière de saluer un travail réellement enrichissant.

$$
\begin{array}{r}
\text { Colin JonES } \\
\text { Université Queen Mary, Londres } \\
\text { Traduit de l'anglais par Karim Ghorbal (IDHE.S) }
\end{array}
$$

Séverine Pilloud,

Les mots du corps. Expérience de la maladie dans les lettres de patients à un médecin du XVIII' siècle: Samuel Auguste Tissot, Lausanne, BHMS, 2013, 367 p., ISBN 978-2-9700640-1-5
Ce livre constitue un apport important à notre connaissance de l'histoire de la seconde moitié du XVIII ${ }^{\mathrm{e}}$ siècle, et une référence essentielle pour l'historiographie qui explore depuis plusieurs décennies l'histoire du corps et des pratiques de santé au quotidien. À la suite

d'historiens comme Roy Porter, Dorothy Porter, Michael Stolberg, Gudrun Piller, Jean-François Viaud et d'autres, qui interrogent les pratiques médicales from below, Séverine Pilloud questionne, dans un style à la fois élégant et précis, différentes 
facettes de la santé, parmi lesquelles la nature et les statuts des savoirs médicaux, le corps et la santé, les influences réciproques des savoirs populaires et de la médecine savante, ainsi que les sens social et identitaire que pouvait prendre un problème de santé à la fin des Lumières. Son travail, comme celui des auteurs cités, contribue à apporter une nouvelle dimension à l'histoire de la santé en introduisant la perspective de l'usager de services médicaux, en alimentant des chantiers bien établis (le marché thérapeutique, les savoirs médicaux, la santé et le genre, l'onanisme, etc.), tout en ouvrant de nouvelles thématiques (le patient, la médiation médicale, la médecine domestique, le parcours de santé, etc.).

La variété des thèmes abordés signale la richesse du travail accompli, mais elle est aussi l'indice d'un risque d'éparpillement. En adoptant un point de vue anthropologique et en se donnant pour objectif d'ériger l'expérience du corps en objet d'histoire, l'auteure assure la cohérence de son travail et échappe à toute thématisation facile. L'ouvrage s'articule autour d'un fonds de sources non médicales relatives à la santé, un corpus de plus de mille lettres adressées au célèbre médecin Samuel Auguste Tissot (1728-1797) par ses patients. À travers ces sources, l'auteure cherche à reconstruire la voix du patient dans la seconde moitié du XVIII ${ }^{\mathrm{e}}$ siècle. La méthode mobilisée est originale, à cheval entre une approche empirique et une analyse littéraire. Elle doit permettre de dégager des «modalités narratives récurrentes susceptibles d'être rapportées à des facteurs socioculturels et historiques" (p. 6), c'est-à-dire de mettre en évidence des traits dans les sources qui peuvent expliquer (ou être expliqués par) d'autres réalités. S. Pilloud n'est pas la première à s'intéresser à ce fonds, mais elle est la seule à avoir tenté une analyse systématique de l'ensemble du corpus.

La source elle-même n'est pas anodine et l'un des premiers points forts du livre est une mise au point sur l'histoire de la correspondance médicale. La pratique d'écrire à un médecin au XVIII ${ }^{\mathrm{e}}$ siècle pour obtenir un avis est reconsidérée, et un survol des fonds européens de correspondance médicale connus permet au lecteur de saisir l'importance à la fois du fonds et de la pratique. Les lettres adressées à Tissot ont été scannées par une équipe dont S. Pilloud fait partie avec Micheline Louis-Courvoisier et Vincent Barras, avant d'être mises à la disposition du public sur une base de données (http://wp.unil.ch/unimedia/tissot/). Grâce à ce travail, il est aujourd'hui possible non seulement d'accéder à la correspondance sur Internet, mais aussi d'isoler une ou plusieurs lettres répondant à des critères précis à partir de mots-clés.

Son approche systématique fait de l'ouvrage une excellente introduction pour celui ou celle qui s'intéresse à la correspondance médicale en général, et au fonds Tissot en particulier. C'est aussi, en raison du travail de contextualisation historiographique en anglais, en allemand et en français qui accompagne l'analyse, une porte d'entrée dans nombre de problématiques actuelles. Les chapitres principaux sont centrés sur la démarche de la consultation, la vie des malades et les représentations médicales et corporelles dans la population. L'auteure montre quels pouvaient être les parcours de santé des patients entre les différents soignants disponibles. Elle décortique l'expérience du corps, définie comme le "résultat d'appropriations de significations relatives au corps et à la santé» (p. 17) et débusque ce qu'elle décrit comme la "culture médicale ambiante" (p. 13) qu'elle confronte, ensuite, aux idées médicales du médecin. Ce faisant, elle met en valeur l'importance de l'automédication et de l'autodiagnostic avant les démarches entreprises auprès de soignants ou 
parallèlement à elles. Les malades avouent recourir à des "empiriques", affichant globalement leur méfiance envers cette catégorie de soignants. Les récits et commentaires sont traités avec finesse, l'auteure considère notamment, et à juste titre, avec un certain scepticisme les critiques à l'encontre d'autres catégories de soignants, tant elles semblent répondre aux idées que les malades se font de la sensibilité du médecin à qui elles sont adressées (p. 134).

Au gré de sa progression, le lecteur recueille une foule d'informations et de détails inédits sur la conception du corps et de la santé, sur les acteurs du marché médical, etc. Au niveau des contenus, l'auteure souligne la nécessité de tenir compte des savoirs laïcs, dévoile avec finesse l'implication des proches dans la gestion de la santé et démontre que seule une lecture contextuelle et littéraire permet d'aborder sérieusement le sens historique de telles sources. Quelques exemples choisis permettront d'apercevoir la richesse des apports de l'enquête. Les correspondants de Tissot affichent une certaine méfiance vis-à-vis des apothicaires, signalant au passage leurs préoccupations à l'égard de la qualité du remède (p. 124-125). Ils établissent des liens entre des événements individuels passés (déficience de leur nourrice, par exemple), des événements importants (la Révolution, le tremblement de terre de Lisbonne) et leur santé (p. 230), et font état de pressions exercées sur le malade (p. 100), tout en communiquant des avis sur différents soignants (p. 154). En somme, l'auteure peut proposer à son lecteur un tableau cohérent et complexe de l'expérience du corps et de la santé à la fin des Lumières.

Les forces de l'ouvrage en conditionnent les limites. Certaines sont clairement identifiées par l'auteure elle-même. C'est le cas, par exemple, de la faible représentativité du corpus : seuls les nantis (nobles et bourgeois) écrivent à Tissot. D'autres sont implicites. En focalisant son attention sur le seul fonds de la Bibliothèque cantonale et universitaire de Lausanne, l'étude néglige les multiples fonds plus petits dans lesquels il serait possible de débusquer des réponses de Tissot à ses malades, des lettres qui compléteraient le corpus existant et permettraient d'approfondir la nature dialogique de la pratique médicale du temps. Par ailleurs, en centrant l'attention sur les lettres écrites à un médecin entre 1761 et 1797, l'auteure propose certes un excellent arrêt sur image des pratiques d'écriture et des stratégies discursives de malades à cette époque, mais fait peu pour intégrer son histoire dans une durée plus longue. Ces limites, que le lecteur curieux regrettera, ne peuvent pas être reprochées à l'auteure qui réalise un travail riche et cohérent. Elles signalent l'ampleur du travail encore à accomplir avant que nous puissions bénéficier d'une histoire de l'expérience de la santé dans le temps long.

Cela étant, face à la complexité de la fresque présentée quel est en définitive l'apport historiographique de l'ouvrage? La réponse à cette question appelle une lecture à plusieurs niveaux. S. Pilloud convainc de la pertinence de son approche et parvient à montrer à la fois que la maladie est socialement et culturellement construite et que les individus (malades ou non) s'approprient des savoirs, négocient avec les praticiens et jouent ainsi un rôle actif dans leur santé. Les malades participent par conséquent à la définition ce qu'est la médecine de leur époque. C'est peut-être là que se trouve le principal apport de l'ouvrage, qui tend à le faire sortir des confins d'un épiphénomène historiographique. La réalité que S. Pilloud dévoile atteste qu'une telle histoire de la santé n'est pas un chapitre à part de l'histoire intellectuelle ou de l'histoire médicale, mais bien un aspect fondamental de la réalité quotidienne à l'époque des Lumières, une réalité qui affectait l'identité des acteurs (le corps dont 
ils héritent), leur confort, leur conception des dangers sanitaires, et qui conditionnait leurs stratégies de vie. À ce titre, le chantier ouvert par S. Pilloud sur l'histoire de l'expérience de la santé mérite d'être poursuivi.

Philip RIEDER Institut Éthique Histoire Humanités, Université de Genève

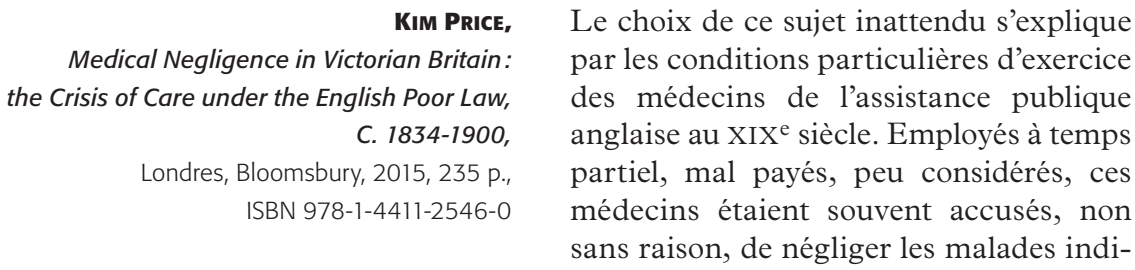
gents. Beaucoup confiaient leur suivi à des "assistants» ou à des infirmières non qualifiées. La plupart d'entre eux avaient par ailleurs une clientèle privée, qui seule leur assurait un revenu décent, et qui leur prenait le plus clair de leur temps. Kim Price explique qu'ils avaient une mission impossible, et que les efforts de quelquesuns d'entre eux, comme le Dr Rogers, pour améliorer leur statut intenable, finirent par dresser contre eux l'opinion publique. De surcroît, dans les trente dernières années du siècle, leur négligence supposée fut instrumentalisée par le Local Government Board pour imposer une politique d'économies (notamment salariales) et de restriction des soins médicaux dans le cadre des workhouses. Dans une visée révisionniste, $\mathrm{K}$. Price rejette donc l'idée de progrès médical au sein de l'assistance publique, y compris dans le dernier tiers du XIX $\mathrm{X}^{\mathrm{e}}$ siècle, où l'ouverture d'hôpitaux de l'assistance a souvent été présentée comme un facteur décisif d'amélioration des soins.

Divisé en deux grandes parties, l'ouvrage traite initialement de la mise en place progressive de médecins de l'assistance à partir de la nouvelle loi des pauvres de 1834 . Celle-ci visait avant tout à dissuader les indigents de demander de l'aide, et organisa un réseau de workhouses punitives. Sous l'autorité de bureaux locaux d'assistance toujours parcimonieux, ces médecins des pauvres étaient chargés de dispenser des soins minimaux et pas toujours éclairés aux indigents. Avant le Medical Act de 1858, qui créa un registre des médecins qualifiés, c'était un groupe hétérogène de praticiens sans formation sérieuse. Les docteurs Griffin et Rogers alertèrent le Parlement sur leurs difficiles conditions de travail, mais n'obtinrent qu'en 1864 qu'ils n'aient plus à financer eux-mêmes les médicaments fournis! Durant tout le XIX $\mathrm{X}^{\mathrm{e}}$ siècle, ils restèrent très mal payés, comme le montrent les statistiques établies par l'auteur. Le salaire des médecins débutants passa seulement de $35 £$ à $55 £$ durant la longue période étudiée, ce qui était par exemple inférieur à celui des maîtres de workhouse.

Après 1860, la révélation dans la presse de plusieurs scandales de malnutrition et de mauvais traitements dans certaines workhouses, que les officiers de santé n'avaient pu prévenir, conduisit le journal médical The Lancet à lancer une grande enquête sur les infirmeries de ces établissements. À la lumière de ses accablantes révélations, le Parlement vota en 1867 le Metropolitan Poor Act qui créa des hôpitaux publics pour les pauvres à Londres, mais sans améliorer pour autant la qualité des soins médicaux dans l'ensemble du système d'assistance. La Poor Law Medical Officers' Association, animée par le Dr Rogers, ne parvint pas à améliorer les conditions de travail de ses 
membres, et c'est en vain qu'elle réclama la création systématique de dispensaires pour les indigents et la protection légale des médecins contre l'arbitraire des bureaux locaux d'assistance. En outre, la "croisade" contre l'assistance à domicile, entre 1870 et 1885, définie par la circulaire Longley, signifia une politique de restrictions budgétaires et une hostilité accrue des dirigeants de l'assistance à l'égard de praticiens toujours suspects de réclamer des dépenses regrettables (notamment le paiement de tâches exceptionnelles), comme le montre la deuxième partie de l'ouvrage.

Les inspecteurs de l'assistance furent les principaux censeurs de ces médecins, dans le dernier quart du XIX siècle. Bien que n'ayant généralement pas eux-mêmes de formation médicale, ils furent pourtant chargés d'enquêter et de statuer sur les «négligences» médicales dénoncées par les bureaux d'assistance ou, plus rarement, par les malades indigents (dont la voix resta souvent inaudible). K. Price, très au fait des questions juridiques, explique que ces inspecteurs n'évaluèrent nullement les éventuelles fautes en termes de préjudice pour les malades, mais en termes de rupture de contrat entre l'autorité d'assistance et le praticien salarié. Il n'était même pas question pour eux de chercher à savoir, comme c'est le cas de nos jours, si le comportement du praticien avait correspondu ou non à une faute proprement médicale. Or les «négligences» rapportées étaient souvent d'ordre purement administratif (mauvaise tenue des registres, absence de rapports écrits aux bureaux d'assistance, par exemple). Sur l'ensemble de la période, il semble ainsi qu'un tiers des médecins de l'assistance aient subi une mesure disciplinaire plus ou moins grave, avec une augmentation des procédures entre 1870 et 1885 .

K. Price consacre aussi un chapitre, beaucoup moins novateur que les autres, à la condition des infirmières des workhouses, qui étaient elles aussi parfois accusées de négligence, et qui pouvaient être punies ou renvoyées du jour au lendemain. Il faut dire que la majorité d'entre elles étaient des femmes indigentes des workhouses, évidemment sans aucune formation. C'est seulement à partir des campagnes de Florence Nightingale que quelques infirmières qualifiées commencèrent à être salariées par des bureaux d'assistance. L'étude de cas consacrée à la mort d'Edward Cooper en 1877, dans la workhouse de l'île de Wight, illustre bien la fatale combinaison de négligences du médecin et des infirmières.

C'est en fin de compte à l'interaction de facteurs différents, aussi bien systémiques qu'économiques et professionnels, que les «négligences» de la médecine des pauvres étaient dues, selon K. Price. Ces praticiens étaient tiraillés entre leur intérêt personnel, leur éthique professionnelle (dont l'ouvrage ne dit pas grand-chose), et les exigences principalement économiques imposées par les bureaux d'assistance. Comme le montre bien ce livre, leurs leaders échouèrent en outre à mettre à profit dans les années 1860 l'émotion suscitée par les grandes enquêtes sur la misère médicale dans les workhouses. On trouvera donc dans ce livre une contribution originale, étayée par des statistiques, des études de cas et quelques documents, sur un aspect méconnu de l'histoire de l'assistance en Angleterre. Malheureusement, sa lecture est rendue malaisée par une certaine tendance à la digression et par d'incessants retours en arrière. 
Olivier Faure, Et Samuel Hahnemann inventa I'homéopathie. La longue histoire d'une médecine alternative, Paris, Aubier, 2015, 395 p., ISBN 978-2-7007-2328-1
Comment écrire l'histoire de deux cent vingt ans d'une sorte de médecine qui fut l'objet d'âpres disputes depuis ses débuts, qui se retrouve actuellement au cœur de débats dans un marché très contesté, et qui est demandée par un

nombre croissant de patients? Olivier Faure relève brillamment ce défi, passant au crible un par un les problèmes que pose cette médecine alternative, sans jamais s'écarter d'une approche critique: pourquoi sans cesse des médecins et des patients ont-ils opté pour un traitement homéopathique malgré la réputation scientifique douteuse de cette médecine? On commence à comprendre quand l'auteur situe "l'invention» de l'homéopathie dans son contexte historique de la médecine des Lumières.

Le médecin fondateur, l'Allemand Hahnemann (1755-1843), commença par refuser les thérapies héroïques, qui font du mal au patient sans servir au traitement. Ensuite, il entama un itinéraire qui allait le mener de la redécouverte du principe de similitude aux prescriptions des très petites doses, en passant par la recherche des effets individuels de chaque substance active. Loin des insinuations du titre du livre (dû à l'éditeur) qui fait de cet homme - souvent adulé par ses disciples - un dieu créateur, l'auteur souligne le caractère autoritaire de ce chef de file, qui pouvait pourtant fasciner, réussit à créer une filière et savait utiliser les médias. Ce qui reste surtout remarquable, c'est qu'il n'arrêta jamais, sa vie entière, d'aspirer à un meilleur traitement pour le patient, démarche documentée quotidiennement par ses journaux de malades. Octogénaire vivant à Paris, il fut ainsi amené à expérimenter avec de très petites doses.

Sa connaissance profonde de l'histoire de la médecine du XVIII ${ }^{\mathrm{e}}$ au XX $\mathrm{XX}^{\mathrm{e}}$ siècle permet à $\mathrm{O}$. Faure de bien situer dans l'histoire des sciences le refus de la majorité des médecins, qui se tournaient plutôt vers un autre paradigme de la maladie. Ensuite, il analyse les soutiens profanes venant des mouvances chrétiennes antimatérialistes, des saint-simoniens spiritualistes, des radicaux anglais, des libéraux américains ou allemands, qui préconisaient le libre choix du patient. En tant qu'historien social, O. Faure situe le profil urbain et géographique des 2 à $4 \%$ d'homéopathes parmi les médecins au milieu du XIX ${ }^{\mathrm{e}}$ siècle: ils ne se distinguent en rien du profil général de la profession en France. Ses observations sont toujours accompagnées de comparaisons avec d'autres pays d'Europe, où l'homéopathie jouait un rôle semblable. Grâce à son excellente connaissance de la bibliographie en langues allemande et anglaise, O. Faure évite ainsi le piège d'une historiographie trop franco-centrée. En revanche, il apporte à l'histoire globale de l'homéopathie une forte touche française, qui rétablit la voix de ce pays très important dans l'histoire de l'homéopathie.

Du vivant même de Hahnemann, le milieu des homéopathes s'était fortement divisé. Originaires d'Allemagne, ces "schismes» avaient des répercussions globales. Les enjeux étaient les suivants : jusqu'à quel degré devait-on diluer? Devait-on donner un médicament unique ou plusieurs substances actives ? Pouvait-on - à la demande du patient (!) - combiner les thérapies héroïques et la saignée avec l'homéopathie, ou non? Fallait-il réserver la pratique aux seuls médecins, ou accepter des praticiens profanes? S'y ajoutaient les réflexes d'exclusion des associations de médecins. Ainsi, l'homéopathie s'affaiblit - après un apogée autour des années 1860 en Allemagne, et seulement après 1900 aux États-Unis et au Royaume-Uni. Aux États-Unis, qui jouissaient d'une infrastructure très développée de medical schools, de laboratoires nombreux et d'une 
recherche clinique de haut niveau, les homéopathes voulaient surtout être reconnus comme médecins et ont eu tendance à abandonner leur spécificité d'homéopathe. Leur inscription dans l'institution médicale a signifié une manière de renoncement identitaire. Cette évolution a eu lieu bien avant les succès pratiques de la médecine bactériologique, qui ne peuvent donc pas l'expliquer. Les homéopathes-médecins voulaient en fait se distinguer des ostéopathes et de leurs autres concurrents, et ils ont ainsi laissé dans une large mesure l'homéopathie aux praticiens profanes. Ceux-ci ont pris la relève en Bavière, mais aussi en Angleterre et aux États-Unis. Cette substitution est assurément moins spécifique à l'Allemagne que l'auteur ne le suggère.

La renaissance de l'homéopathie a pris des chemins très différents selon les pays. Pendant l'entre-deux-guerres, quelques représentants influents de la médecine universitaire allemande et française ont fait état d'une "crise de la médecine», se référant à ses limites thérapeutiques, et ont promu une reconsidération de l'homéopathie. Le gouvernement nazi s'intéressa un court moment à toutes les médecines alternatives - dans un contexte de mobilisation de ressources préparant la guerre - avant d'abandonner tout projet de reconnaissance officielle. Ce n'est qu'en 1956 que l'homéopathie fut reconnue comme l'une des multiples spécialisations médicales par la profession allemande. En France, Vannier et les Laboratoires homéopathiques de France ont choisi la voie de la formation continue des médecins, pour faire connaître le médicament homéopathique comme alternative ou complément thérapeutique. Depuis les années 1980, la demande des patients augmente et, en 2009, plus de 50\% des Allemands et des Français ont eu recours régulièrement à des médicaments homéopathiques. D'autres pays d'Europe comme l'Italie ou la Norvège suivent cette tendance lourde, partant d'un niveau plus bas. Même dans les pays qui étaient sous influence soviétique, l'intérêt pour l'homéopathie a resurgi depuis 1990 - après un demi-siècle de «mise au placard» comme médecine «non scientifique». L'homéopathie n'y fut pourtant jamais totalement interdite.

La demande des patients est assurément l'une des raisons de la longévité de l'homéopathie. Le caractère élitiste d'une partie de la clientèle des premières décennies a sans doute contribué à l'acceptation initiale de cette forme de médecine. Il faut remercier $\mathrm{O}$. Faure de rendre justice à l'histoire de cette pratique par la qualité et la lisibilité de ce beau livre.

Martin DINGES Institut für Geschichte der Medizin der Robert Bosch Stiftung, Stuttgart

ELLen J. Amster,

Medicine and the Saints. Science, Islam and the Colonial Encounter in Morocco, 1877-1956,

Austin, University of Texas Press, 2013, 334 p., ISBN 978-0-292-74544-5
Cet ouvrage propose de l'histoire du Maroc colonial et postcolonial une lecture «incarnée» (embodied), qui voudrait placer le corps au cœur de l'analyse politique. En contexte colonial, cet angle d'approche permet de saisir les zones de contact, les emprunts mutuels et les appropriations des savoirs coloniaux et «indigènes» mais aussi l'empreinte qu'a laissée l'entreprise coloniale sur le Maroc postcolonial.

Ellen J. Amster utilise une grande variété de sources, en langue principalement française - archives coloniales, travaux de sociologues, d'administrateurs et de médecins français au Maroc, traductions françaises de traités de médecine arabes - auxquelles s'ajoutent des manuscrits de médecine en arabe, et une quinzaine d'entretiens conduits au Maroc entre 1995 et 2012, en arabe marocain d'après les extraits cités dans le texte. 
Dans un style fluide et agréable qui maintient l'attention du lecteur de part en part, l'auteure multiplie les cas concrets qui donnent à voir le rapport entre savoir et pouvoir dans l'entreprise coloniale, et montrent comment les Marocains, et les Marocaines en particulier, se sont saisis des techniques et des ressources de la médecine française pour les adapter à leurs propres pratiques et pour s'émanciper de la tutelle coloniale.

Le premier chapitre est consacré à la sainteté et au soufisme comme construction du corps politique et de l'histoire commune, mais aussi comme guérisseurs du corps et de la communauté des croyants, dès le XVII siècle à partir de l'exemple de la ville de Fès. Le rôle central des saints de cette ville dans la mémoire collective et la vie politique comme dans la constitution du savoir fut remis en cause, nous explique l'auteure, par le sultan Abd al-Hafiz (1908-1912) afin d'asseoir sa légitimité politique contestée. Le modèle politique soufi aurait ainsi laissé place à la pensée islamique moderniste, la salafiyya (p. 50) qui soustrait la médecine et la guérison à la sainteté.

Le deuxième chapitre examine la façon dont l'hygiène et la sociologie sont allées de pair au Maroc colonial, pour combattre la «mentalité» marocaine envahie par les croyances magiques, à la faveur d'un positivisme inspiré d'Auguste Comte. La conception de Lyautey était celle d'une conquête pacifique par la science, tout en différenciant racialement les "Européens" des "musulmans». Il s'agissait ainsi de modeler, par l'apprentissage de l'hygiène et l'imposition de normes françaises, le corps même des Marocains. E. J. Amster souligne que les intellectuels musulmans salafis reprirent les idées positivistes à leur propre compte, revendiquant une société moderne et épurée des superstitions attribuées au soufisme.

À partir du cas de l'assassinat du Dr Mauchamp en 1907, l'auteure met en évidence, dans le troisième chapitre, le rôle des médecins français comme agents coloniaux, malgré un engagement réel de leur part pour la santé des populations. Des rumeurs rapportées dans différentes sources témoignent de l'image, répandue parmi les Marocains, des médecins français vus comme des espions, chargés d'inoculer des maladies aux populations locales afin de les affaiblir. Par ailleurs, ce chapitre remet en cause les approches essentialistes distinguant sciences exactes européennes et médecine islamique, par la constatation d'une similarité forte de la vaccination dans la conception européenne et dans la conception islamique.

L'étude précise de certaines maladies (paludisme, peste, typhus, typhoïde) permet de comprendre la façon dont le protectorat orientait sa politique médicale selon les appartenances raciales, en fonction de l'inégal accès à l'eau dans les villes par exemple. Les Marocains étaient vus comme des foyers de maladie dont il fallait se préserver. C'est ainsi que «les promesses et les échecs de l'hygiène française ont produit non pas un solidarisme franco-musulman, mais une politique nationaliste et un nouveau civisme dans les villes musulmanes marocaines» (p. 141). La prise de conscience de l'inégalité profonde entre "indigènes» et «Européens» dans l'accès aux soins et à l'hygiène favorisa les revendications nationalistes symbolisées par le Plan de réformes marocaines de 1934, qui prévoyait un système de santé public et centralisé.

Les chapitres 5 et 6 mettent en évidence l'importance des femmes pour les politiques de santé publique du protectorat. C'est l'un des apports majeurs de l'ouvrage. Le rôle des femmes marocaines était prédominant dans la société, pour les soins liés à l'enfantement, à la pharmacologie familiale, et à l'expertise en médecine légale dans toutes les affaires concernant des femmes, correspondant aux fonctions de qabla (sage-femme traditionnelle), arifa (autorité médicale) et adala (experte légale). Associé à la politique de non-ingérence dans les affaires familiales du protectorat, ce rôle central compliqua 
l'accès des médecins français aux foyers marocains. Mais le recours à des médecins françaises femmes et le développement de maternités sur le territoire permirent progressivement au pouvoir colonial de s'approprier les corps des femmes. Il modifia ainsi les conditions d'accouchement, pour les cas les plus difficiles qui seuls étaient amenés dans les hôpitaux, perçus comme le dernier recours, preuve de la prééminence des qabla dans la société; il changea également les habitudes des jeunes mères, en formant les femmes marocaines à l'hygiène et la puériculture. L'auteure analyse précisément les théories de Galien utilisées dans les pratiques traditionnelles d'accouchement et de soins aux nouveau-nés, pour mettre en évidence la jonction progressive de ces pratiques avec les recommandations des centres de Protection Maternelle et Infantile (PMI) mis en place par le protectorat.

De nombreuses futures infirmières et sages-femmes du Maroc indépendant furent formées dans les centres de PMI, ce qui marque la continuité avec le système de santé postcolonial au Maroc. De son côté, le nationalisme marocain revendiqua la défense de la famille musulmane et de la santé des Marocains, en opposition aux politiques coloniales, tout en «adoptant le langage positiviste français de la science» (p. 208) et en intégrant la biomédecine comme un droit pour chaque citoyen. Le projet français de maîtriser les corps par la loi et la bureaucratie, "pouvoir biopolitique», se retrouve ainsi dans le Code du statut personnel marocain adopté en 1957 (Mudawwana).

Dans l'épilogue de l'ouvrage, E. J. Amster décrit, à partir d'entretiens menés dans les années 1990, le pluralisme médical issu de la période coloniale, à mi-chemin entre les pratiques traditionnelles et la biomédecine. La contestation politique par la critique de l'accès au soin et la définition de soi par le rapport au corps dans le Maroc postcolonial sont deux axes majeurs de sa conclusion, qui réaffirme la volonté de l'auteure d'ancrer le corps comme facteur d'analyse du politique.

L'intérêt de ce travail pour l'historien du Maghreb est qu'il n'est pas seulement une analyse de la médecine au Maroc à l'époque coloniale et de l'entreprise coloniale française. Il livre une histoire sociale des femmes et de la famille, qui contribue au mouvement historiographique s'attachant, depuis les années 1990, à renouveler l'histoire des femmes au Maghreb. Ce livre donne également des clés pour percevoir l'importance de la spiritualité et du mysticisme dans l'imaginaire collectif et les réalités sociales au Maroc.

C'est en cela qu'il est surprenant que l'auteure tende, surtout en début d'ouvrage, à catégoriser de façon trop rigide une opposition entre soufis et salafis partisans d'un islam rationnel, qui auraient fait "disparaître les saints en tant que leaders politiques» (p. 50). Si l'auteure n'ignore pas le modernisme soufi mobilisant l'idée de tajdid (renouvellement) - rapidement évoqué p. 46-48 - il eût toutefois été possible de nuancer davantage la domination de l'islam soufi dans le Maroc indépendant par un islam salafi porté par les nationalistes, dont E. J. Amster situe l'ancrage originel dès le règne du sultan Abd al-Hafiz (1908-1912). Le parti nationaliste ('Istiqlal) prônait certes une vision salafi de l'islam, mais la politique royale favorisa dès les années 1960 le respect des pratiques liées au culte des saints "dans le respect de la tradition makhzénienne" par la restauration de mausolées et la réhabilitation des pèlerinages annuels (moussems) et des dons aux saints. L'auteure reconnaît pourtant, dans l'épilogue, l'omniprésence du soufisme et de la sainteté au Maroc jusqu'à la période contemporaine. Cela ne saurait toutefois ternir l'apport important de cet ouvrage pour l'histoire du Maroc colonial et postcolonial. 
Stéphane Frioux,

Les batailles de I'hygiène. Villes et environnement de Pasteur aux Trente Glorieuses,

Paris, PUF, 2013, XXIII + 388 p.,

ISBN 978-2-13-061786-0
Stéphane Frioux décrit son travail, un mariage d'histoire sociale et environnementale, comme «une démarche [...] encore rare dans l'historiographie française de l'environnement urbain" (p. 5). L'originalité dont il se réclame est peut-

être exagérée. Néanmoins, à côté des travaux de plus en plus nombreux explorant la façon dont la France est devenue une nation plus propre et plus saine (notamment ceux de Fabienne Chevalier, Patrice Bourdelais, Alain Corbin, Julia Csergo, Jean-Pierre Goubert, Jacques Léonard et Georges Vigarello), il fait le choix de se concentrer sur un aspect moins étudié de cette histoire: plutôt qu'un récit narrant une inévitable quoique spasmodique marche vers le progrès, ou une histoire sordide décrivant le combat des élites françaises contre la révolution ouvrière par «l'embourgeoisement» des manières, l'auteur se focalise sur les luttes concrètes qu'il a fallu mener au niveau local à travers tout le pays pour ramasser les ordures, nettoyer les canalisations d'égouts ou fournir au peuple de l'eau potable. La «bataille pour l'hygiène» s'est révélée un chemin semé d'embûches, qu'elles soient technologiques, financières ou politiques.

L'hygiène commence toujours par l'eau. Les autorités politiques de l'Ancien Régime avaient déjà tenté, sans réel succès, d'approvisionner en eau les cités françaises. Quand il est devenu clair, lors de la seconde moitié du XIX ${ }^{\mathrm{e}}$ siècle, que l'eau polluée était la source de nombreuses épidémies dévastatrices comme le choléra ou la typhoïde, les besoins en eau propre sont devenus de plus en plus criants. En outre, la production de déchets des villes en expansion s'accroissait, ainsi que la nécessité d'évacuer cette production. Le fumier et les déchets organiques étaient utiles à l'agriculture, et les villes modestes, proches des campagnes, avaient toujours la possibilité de les y transférer, ou d'inviter les fermiers locaux à les emporter. Mais les villes plus importantes engendraient beaucoup plus de déchets, sans avoir la possibilité de les évacuer facilement dans leurs hinterlands, et faisaient donc face à un défi d'envergure.

Pasteur, plus que quiconque, fut le réel initiateur de la course à l'eau propre, en convainquant la plupart des Français que les épidémies étaient, comme l'a dit l'historien du choléra Steven Johnson, le produit d'une ingestion et non d'une inhalation. Le besoin d'éradiquer les épidémies "évitables", encore plus que le désir d'éliminer les "odeurs nauséabondes", fut le point de départ de la quête d'un procédé de purification de l'eau. Les progrès de cette croisade furent inégaux. Au tournant du siècle par exemple, $84 \%$ des constructions parisiennes étaient raccordées au réseau d'eau courante; dans le reste du département de la Seine, c'était moitié moins. Pendant ce temps, les 30000 habitants de la "cité des papes", Avignon, utilisaient encore l'eau des puits à la veille de la Première Guerre mondiale.

S. Frioux commence son livre par l'exemple de Cosne-sur-Loire dans la Nièvre. Peuplée de 7200 habitants, hébergeant une importante garnison militaire, Cosne ne possédait aucun système de distribution d'eau potable en 1900, malgré sa proximité avec l'une des plus grandes rivières du pays. En 1904, grâce à d'ambitieux responsables locaux et à la pression de l'armée, qui voulait protéger ses soldats de la typhoïde, Cosne est devenue un modèle national de progrès, avec un système de traitement des eaux s'appuyant sur la méthode nouvelle de "l'ozonification». Malheureusement, toutes sortes de difficultés ont empêché ce système de fonctionner correctement, dont des problèmes de maintenance occasionnés par son coût, particulièrement quand la ville a 
perdu son ingénieur en chef à la guerre. À l'heure où Cosne célébrait le centenaire de Pasteur en 1923, le système était sur le point de s'effondrer. Moralité: même lorsque les barrières habituelles que sont le financement, la technologie et les réticences politiques étaient franchies, l'approvisionnement en eau potable était loin d'être assuré.

L'autre problème lié à la fourniture d'eau potable fut la question de l'évacuation des eaux usées, que les villes modernes produisaient en abondance. Les solutions héritées de la fin du XIX ${ }^{\mathrm{e}}$ siècle (fosses fixes et drains à ciel ouvert, couplés à un système limité de canalisation d'évacuation des eaux de pluie) étaient incapables de faire face à l'océan toujours grossissant des eaux usées. Les solutions techniques disponibles (construire de nouveaux égouts puis trouver un moyen de les décontaminer) requéraient des investissements plus lourds encore que ceux nécessaires à la purification de l'eau.

Restait à traiter le problème des déchets solides (c'est-à-dire des ordures), sous ses deux formes: collecte et élimination. La collecte, quoique difficile à mener, était en fait assez simple à concevoir. Eugène Poubelle, préfet de la Seine, imposa ses réceptacles à ordures éponymes dans les années 1880, et son système se répandit assez vite dans les autres villes. Le problème technique le plus difficile à résoudre était de savoir que faire des montagnes de détritus collectés. Les éléments organiques pouvaient être récupérés par les agriculteurs afin de fertiliser leurs champs, même si le guano d'importation et les phosphates industriels se sont révélés plus efficaces que les boues urbaines pour nourrir les sols. Le reste était généralement entassé dans des emplacements plus ou moins distants, ou incinéré dans les cas où la technologie était mise à contribution. L'incinération requérait néanmoins de construire et d'entretenir des installations qui accroissaient le coût de ces réformes et donc les conflits politiques qu'elles généraient. À ces difficultés techniques et financières s'ajoutait, comme le souligne l'auteur, le problème NIMBY (de l'acronyme Not In My Back Yard), qui rendait les populations locales, y compris les personnes désireuses de payer pour ces installations, incapables d'admettre que ces dernières puissent s'établir à proximité de leur résidence.

Le plus grand apport de ce livre réside dans la manière dont il insère ces éléments d'assainissement dans le contexte plus général d'un ensemble de choix disputés et discutés, constitutifs de cette "bataille pour l'hygiène»: devons-nous construire un complexe de purification de l'eau, couplé à un système d'égout et à un incinérateur? Où pourrions-nous l'installer? Laquelle des différentes technologies en présence devrions-nous adopter? Et comment allons-nous financer tout ceci?

Nous pourrions croire que ces disputes locales à propos de l'hygiène épousaient les lignes de fracture politique habituelles. En réalité, S. Frioux considère qu'«il n’y a pas vraiment de politique urbaine d'ingénierie sanitaire de gauche ou de droite, mais des rivalités locales, des contextes sociaux, des choix de modes de financement ou de gestion et des contraintes budgétaires propres à chaque agglomération" (p. 319). Avant 1914, quand la plupart des conseils municipaux réformateurs inclinaient à gauche ou au centre-gauche, les différentes politiques menées reflétaient des désaccords personnels ou techniques plutôt qu'idéologiques. Par ailleurs, les coûts élevés et le retour sur investissement incertain d'une politique d'hygiène forçaient toutes les municipalités, quelles que soient leurs orientations politiques, à se montrer prudentes.

Les décisions techniques et financières auraient dû être plus faciles à prendre si avaient été prises en compte les expériences des autres villes, qu'elles soient françaises ou étrangères. L'Allemagne et la Grande-Bretagne offraient des dizaines d'exemples réussis de systèmes d'assainissement des eaux. L'auteur dresse ainsi un portrait ambigu 
de la coopération internationale dans le domaine de l'hygiène urbaine. Il souligne d'une part les nombreux transferts de compétences à travers le pays, l'Europe et de manière occasionnelle en provenance du continent américain. Les ingénieurs et les hygiénistes se rencontraient lors de conférences; les autorités locales n'hésitaient pas à contacter leurs homologues en quête d'informations et de conseils; les hommes d'affaires souhaitaient vendre leurs technologies par-delà les frontières nationales. D'un autre côté, il affirme que les communes françaises étaient entravées par leur chauvinisme technologique, préférant les entreprises françaises et leurs solutions plutôt que leurs concurrentes étrangères, bien souvent supérieures. D'une manière sans doute surprenante, l'exemple parisien n'a pas eu d'effet d'entraînement sur le reste de la France urbaine. On a longtemps cru que les réformes suivaient un modèle linéaire, où les petites agglomérations empruntaient leurs solutions aux plus grandes, et où la périphérie s'inspirait du centre. L'auteur ne trouve pourtant aucun fait corroborant cette hypothèse concernant l'évolution de l'hygiène urbaine.

L'enquête suggère que les obstacles au progrès résultaient dans une large mesure $\mathrm{du}$ fait que les autorités locales ne ressentaient pas de pression suffisante de la part de leurs administrés en faveur d'une amélioration de l'hygiène - excepté le désir naturel mais flou de ne pas mourir de la fièvre typhoïde ou du choléra. Face à la réticence généralisée à payer plus d'impôts pour financer les travaux de construction, ou face à l'opposition de ceux qui étaient affectés par ces travaux (comme les propriétaires qui refusaient d'assumer les coûts de connexion de leurs biens immobiliers au réseau d'égout), la demande d'eau potable ou le désir de rues sans déchets n'étaient le plus souvent pas suffisants pour infléchir les politiques suivies. Une autorité centrale plus déterminée aurait pu exercer une pression plus forte sur les autorités municipales, et faire une différence décisive en fournissant l'argent nécessaire pour lancer les projets locaux. Néanmoins, bien que l'Assemblée nationale ait voté des lois exigeant une France plus propre, elle ne s'est pas souciée du financement de cette ambition.

$S$. Frioux montre également que même lorsque volonté et énergie étaient présentes au niveau municipal, les progrès furent lents. Édouard Herriot, maire réformateur de Lyon de 1905 à 1957, était bien sûr un homme d'une immense influence au niveau national. Au milieu des années 1930 pourtant, Lyon ne possédait toujours pas un système fonctionnel de collecte des ordures et, en 1928, la ville fut ravagée par une épidémie de fièvre typhoïde, en raison d'une absence de système efficace de purification des eaux.

Ces différentes «batailles pour l'hygiène» ont fait de la France un pays situé au milieu du peloton européen, derrière les pays du Nord mais devançant ceux du Sud - ou pour l'exprimer d'une autre façon, en tête de l'Europe catholique mais derrière l'Europe protestante. Même au sein des frontières hexagonales, les villes du Nord et de l'Est étaient en général plus propres et en meilleure santé que celles du Sud et de l'Ouest. Cette situation était peut-être due au climat, à la culture, aux institutions locales ou à toute autre variable, mais l'auteur se garde bien de trancher parmi ces différentes hypothèses.

En somme, Les batailles de l'hygiène est un travail riche en informations concernant les à-coups et les tentatives inabouties pour promouvoir la "propreté» en France durant la période bornée par la diffusion de la théorie des germes et la fin des «Trente Glorieuses». La structure du livre n'est ni thématique ni chronologique, ce qui parfois entraîne des redites et en rend la lecture difficile. Je me demande également si, tout à sa volonté de démêler les nœuds constitutifs de la réforme urbaine, l'auteur 
ne sous-estime pas le rôle fondamental de l'argent. Les rivalités personnelles, les inquiétudes concernant les différentes technologies proposées et d'autres difficultés ont bien sûr entravé ce processus. Mais derrière la plupart des manifestations d'opposition aux travaux publics était tapie la question de savoir qui allait payer et de quelle façon. En général, les autorités possédaient plus d'ambitions que de ressources. En effet, la pauvreté relative de l'État français explique dans une large mesure pourquoi le pays, qui réfléchissait à la manière de rendre ses cités plus propres dès l'Ancien Régime, n’a finalement réalisé cette tâche que dans les années 1960 et 1970: la croissance économique de l'après-guerre a simplement transformé la France en un pays riche, enfin capable de construire des infrastructures d'hygiène modernes. Cela étant dit, S. Frioux a apporté une superbe contribution à notre compréhension du processus de modernisation, en nous forçant à considérer l'assainissement de la France comme une période historique riche d'espoirs déçus et de conflits, mais en fin de compte fructueuse.

Steve ZDATNY

Université du Vermont (États-Unis)

Traduit de l'anglais par Karim Ghorbal (IDHE.S)

\begin{abstract}
MARIOn Fontaine,
Dans cet ouvrage issu de sa thèse, Le Racing Club de Lens et les "Gueules noires». Marion Fontaine tord brillamment le Essai d'histoire sociale, Paris, Les Indes savantes, 2008, 292 p., cou à certaines idées reçues concerISBN 978-2-84654-248-7 nant l'histoire du football en France. La première d'entre elles en fait un sport "ouvrier" - bien que l'on sache depuis
\end{abstract} l'étude de Loïc Ravenel (La géographie du football en France, 1998) que sa diffusion dans la société française doit beaucoup aux structures d'encadrement du monde catholique en milieu rural - caractère ouvrier qu'incarnerait par exemple l'Association sportive de Saint-Étienne (ASSE), le club le plus titré du pays et longtemps le plus populaire, ou, dans une moindre mesure, le Racing Club de Lens (RCL), champion de France en 1998, dans le stade duquel résonne encore aujourd'hui les jours de match Les corons, la chanson de Pierre Bachelet retraçant la geste des mineurs du Nord. Or, à l'instar de l'ASSE qui a pu «être présentée comme l'envers de la ville noire, beaucoup plus que comme son reflet» (p. 204), l'identification du Racing Club de Lens au groupe social des mineurs - par ailleurs disparu puisque le dernier puits lensois ferma en 1986 - n'avait rien d'évident. Elle fut le fruit d'une histoire heurtée, mettant aux prises tout au long du $\mathrm{XX}^{\mathrm{e}}$ siècle différentes classes sociales (la petite bourgeoisie du centre-ville, les mineurs des corons, le patronat des Houillères) et institutions (la municipalité de Lens, l'entreprise minière, les organisations ouvrières implantées dans le bassin). Le propos de l'auteure n'est donc pas de se livrer à une monographie uniquement sportive du RCL mais «de saisir ce qui se joue autour de lui et à travers lui, de discerner la configuration mouvante, ancrée dans le territoire lensois et dont il a été un élément» (p. 18).

La mise en œuvre de cette recherche d'histoire totale, à la fois sociale, culturelle, politique et économique, suit un développement chronologique. La première partie ("Le football à la conquête de Lens-les-Mines») montre comment les mineurs et leur famille, cantonnés dans les cités minières appartenant à la Société des Mines, étaient bien loin du football, culturellement - ils lui préféraient la colombophilie, 
entre autres - et spatialement - le RCL avait été fondé en 1906 par des «établis» du centre de Lens (des commerçants, des petits entrepreneurs, des fonctionnaires). Lorsque Félix Bollaert, le président du conseil d'administration des Mines, inaugure en 1933 le stade qui porte son nom à la lisière entre les deux parties de la ville, c'est d'ailleurs une démonstration de gymnastique qui y est organisée. Le football ne vient aux mineurs que par le biais de la reconfiguration des politiques paternalistes de la Société des Mines: en 1934, probablement inspirés par les industriels du textile de Roubaix qui financent l'Excelsior ou par la famille Peugeot à Sochaux - sans compter les exemples étrangers de Philips à Eindhoven, de Bayer à Leverkusen et de la FIAT à Turin -, les dirigeants des Mines de Lens rachètent le RCL et, en quatre ans, le font intégrer la première division du championnat de France, professionnel depuis 1932. Élément du prestige de la compagnie, le football est également conçu comme un moyen de discipliner la jeunesse et de lui apprendre le respect de l'autorité et de la hiérarchie. En retour, les mineurs, s'ils le pratiquent de plus en plus, ne l'adoptent pas pleinement et le considèrent en partie comme étranger à leur monde et à leurs formes propres de sociabilité où prédominent encore des loisirs plus anciens.

Dans cette optique, la Libération constitue un tournant, analysé dans la deuxième partie ("L'avènement du RCL»). Une nouvelle génération de militants, membres du Parti communiste, abandonne toute réticence vis-à-vis du club des Mines, qui dépend désormais des Houillères nationales du Bassin Nord-Pas-de-Calais créées par la loi de nationalisation de 1946. Comme le note M. Fontaine, "les communistes ne se contentent pas d'accepter le RCL, ils le font», ce qui révèle "la manière dont [le PCF] parvient à porter le "Nous" ouvrier" (p. 106). Ainsi, c'est la presse communiste, notamment l'hebdomadaire sportif régional Liberté-Sports, qui transforme le RCL en "club des Gueules noires", lui donne de ce fait un sens politique, et cherche "à en faire un support de légitimité, en nouant sur des bases sportives l'appartenance ouvrière et lensoise à l'appartenance communiste» (p. 118). Un dimanche sur deux, le stade Bollaert devient l'enceinte où se déploie dans l'enthousiasme l'affirmation de la pérennité et de l'unité du groupe des mineurs qui fondent l'influence politique du PCF dans la région. La force d'une telle fonction sociale et symbolique conduit la direction des Houillères, après les dures grèves de 1947-1948, à approfondir et renouveler les modalités du paternalisme sportif dont les bases avaient été jetées dans les années 1930. Le spectacle sportif doit permettre d'apaiser les conflits sociaux et d'encadrer la "grande famille" des mineurs en détournant ces derniers du militantisme syndical. Alors que les Houillères ont encore besoin de main-d'œuvre pour poursuivre l'extraction du charbon, il s'agit de stabiliser et d'enraciner la population des corons: le personnel dirigeant des Mines s'implique ainsi dans le fonctionnement du club et notamment dans la sélection des meilleurs footballeurs-mineurs. Pour les familles de ces derniers, en particulier celles de la deuxième génération d'immigrés polonais, l'excellence footballistique constitue dès lors un moyen non de quitter le monde de la mine mais de progresser dans la hiérarchie ouvrière. Les années 1950 et 1960 constituent ainsi l'apogée de ce double mécanisme d'encadrement, communiste et patronal, qui consacre le RCL comme le support privilégié de la fierté collective des mineurs.

Le club parvient ensuite à survivre à l'entrée "dans la crise du monde minier", à laquelle est consacrée la troisième partie, grâce aux efforts de la municipalité socialiste dirigée par André Delelis. En accordant au RCL des subventions toujours plus élevées dans les années 1970 et 1980, puis en présidant à sa transformation en 
entreprise commerciale intégrée au marché européen du football dans les années 1990, les édiles socialistes comptent sur la capacité de ce sport à incarner la modernisation de leur ville. Aussi l'ancien club des «Gueules noires" devient-il le «lieu et le symbole» de l'émancipation des Mines: alors que "les communistes encouragent le RCL au nom de "Lens-les-Mines", les socialistes raisonnent et agissent au nom de "Lens la ville"” (p. 205). L'entreprise est couronnée de succès, tant et si bien que dans les dernières décennies du $\mathrm{XX}^{\mathrm{e}}$ siècle les supporters du RCL, originaires de tout le Nord-Pas-de-Calais, toujours plus nombreux et exubérants, envahissent régulièrement le centre-ville de Lens à l'occasion des matchs, assurant enfin la continuité du corps urbain. Le club de football en vient à jouer un rôle de compensation symbolique au déclin industriel et au déclassement régional. Étrange paradoxe relevé par M. Fontaine: "Les valeurs et les images dont était porteur le "club des Gueules noires" persistent, alors même que certains de leurs supports médiatiques (la presse des Houillères, celle du Parti communiste), sociaux (la domination des mineurs dans le stade) et institutionnels (l'encadrement du public dans le cadre des cités) s'effacent ou se rétractent" (p. 229).

En définitive, cette recherche d'excellente qualité, servie par un style toujours clair et précis, apporte beaucoup à l'histoire du football et du sport en France, et plus généralement à l'histoire sociale, politique et culturelle du monde ouvrier et de ce qui fut l'un des plus grands centres miniers d'Europe. Ce n'est pas le moindre de ses mérites.

Fabien ARCHAMBAuLt CRIHAM-Université de Limoges 